\title{
Las tesis panteístas de Isaac Newton
}

\author{
JosÉ A. RoBLES \\ Instituto de Investigaciones Filosóficas \\ Universidad Nacional Autónoma de México \\ jrobles@servidor.unam.mx
}

RESUMEN: En este escrito, análisis de algunas tesis teológicas de Newton que figuran en su texto de publicación póstuma, "De gravitatione et æquipondio fluidorum" (ca. 1668), sostengo que su autor mantuvo una posición panteísta que aún permanecerá en obras posteriores, como en su Opticks (1704) y en el "Escolio general" al "Sistema del mundo" en las ediciones de 1713/1726 (2a. y 3a.) de su prodigiosa obra Philosophiæ naturalis principia mathematica.

Además de dar argumentos en apoyo de la conclusión señalada con respecto a la posición de Newton, también considero dos interesantes propuestas sobre la Creación, la de Juan Escoto Erígena (ca. 810-877) y la del cabalista judío del siglo XVI, Isaac Luria (1534-1572), quienes fueron considerados panteístas (las propuestas del pensador irlandés fueron condenadas por el Concilio de París de 1210, 333 años después de su muerte) aun cuando ellos no tuviesen este designio.

Finalmente, intento darles sentido a las tesis teológicas de Newton dentro de un contexto de filosofía natural.

PALABRAS ClaVE: filosofía natural, historia de la filosofía, Newton, teología.

\section{PRESENTACIÓN*}

En un escrito anterior, "Isaac Newton: ¿berkeleyano avant la lettre?", ${ }^{1}$ presenté las propuestas de Newton, en su obra de publicación póstuma, "De

* Parte de este artículo lo presenté como ponencia en el V Coloquio Bariloche de Filosofía (28-30 de junio de 2000) y una versión corregida aparecerá en la Revista Patagónica de Filosofía. Deseo agradecer la amable invitación de Oscar Nudler para participar en el ya tradicional Coloquio. Una versión diferente, con el título "Newton: ¿creacionista heterodoxo?", la expuse en el I Congreso Iberoamericano de Filosofía de la Ciencia y la Tecnología, llevado a cabo en Morelia, Mich., México (25-29 de septiembre de 2000) y, finalmente, en este mismo año (9-13 de noviembre), en Aguascalientes, en el (XIII) Encuentro Nacional de Investigadores: Pensamiento Novohispano, presenté la ponencia intitulada "Las tesis panteístas de Isaac Newton", basada, de manera central, en el presente trabajo. A Roberto Heredia y a Mauricio Beuchot les agradezco, como siempre, la invitación a esta cada vez más importante reunión anual. A Mauricio y a Laura Benítez les reitero mi agradecimiento por la minuciosa lectura que hicieron de mi texto, y a esta última las múltiples sesiones en las que hemos analizado diferentes aspectos de los escritos de Newton, lo que me ha permitido aclarar muchas de mis ideas acerca de las complejas relaciones y opiniones que el autor inglés tiene sobre filosofía natural y teología.

1 [59] en la Bibliografía. 
gravitatione et æquipondio fluidorum", ${ }^{2}$ en las que el autor inglés formulaba tesis inmaterialistas, con respecto al mundo perceptual, muy similares a las que Berkeley expresaría años después (ca. 1708-1710) y, además, expuse un alegato para convencer a mis lectores de que, en ese ensayo, Newton debería sostener (al igual que Berkeley) ${ }^{3}$ una tesis ocasionalista con respecto a los resultados de las voliciones de los espíritus creados, tendientes a mover sus propios cuerpos.

En ese mismo texto espero haber mostrado algo de suma importancia, a saber, que en las doctrinas de ambos pensadores (Newton y Berkeley) hay una coincidencia casi puntual en su afán de señalar (por motivos similares) que la doctrina cartesiana sobre la sustancia material o res extensa es ininteligible y lo negativo que consideran que de ella se deriva: el escepticismo, la irreligión y, finalmente, el ateísmo, así como el error en la filosofía natural. ${ }^{4}$ Ambos pensadores se imponen la tarea de dar con la forma de generar sendas doctrinas que no tengan semejantes consecuencias y son en estas formulaciones anticartesianas para erradicar el escepticismo, fortalecer la religiosidad, dar una prueba de la existencia de Dios y formular una filosofía natural que concuerde con los hechos y los explique, en las que hay un muy notable parecido.

De manera más precisa, las tesis que presenté y defendí en el escrito mencionado fueron:

1. Newton rechaza que los cuerpos sensibles requieran de un sustrato material, de inherencia de cualidades;

para ello, propone:

2. una tesis sobre la Creación, en la que Dios sólo se vale de porciones de espacio y las dota de cualidades sensibles, justamente aquellas que Descartes había rechazado como pertenecientes a los cuerpos materiales $^{5} \mathrm{y}$, además, nos dice que Dios puede cambiar de lugar estos cúmulos de cualidades; estos cuerpos, entonces, pueden interpretar-

2 Westfall, en [72], p. 301, calcula su fecha de redacción en, al menos, 1668.

3 Acerca de esto, véase mi [56].

4 El título completo de la obra central de Berkeley, al respecto, es: Un tratado concerniente a los principios del conocimiento humano, en el que se investigan las causas del error y de la dificultad en las ciencias, con los fundamentos del ateísmo y de la irreligión.

${ }^{5}$ La propuesta de Newton está fuertemente relacionada con lo que nos dice Dionisio, el seudo Areopagita, acerca de la presentación sensible que Dios hace de sus ideas: "Pero como nosotros entendemos a través de los sentidos, según nuestra capacidad, el amor que Dios nos tiene envuelve lo inteligible en lo sensible..." [En [23], 1 [592B], p. 273]. Es una propuesta como ésta la que adoptará Berkeley en su doctrina inmaterialista: el mundo sensible son las ideas que Dios hace sensibles para que nosotros las podamos percibir. Pero, ciertamente, es Malebranche quien adopta la doctrina de manera más plena al sostener que Dios modifica 
se, a la manera berkeleyana, como las ideas de Dios, que el Creador muestra a los espíritus creados; 6

a partir de esta tesis, muy similar a la posterior tesis inmaterialista de Berkeley, considero que Newton se ve obligado a adoptar:

3. una propuesta de tipo ocasionalista para dar cuenta de los resultados de las voliciones (efectivas) de los espíritus creados para mover los cuerpos sensibles, incluidos sus propios cuerpos. ${ }^{7}$

Con base en lo anterior, nuestro autor considera que muestra:

4. la íntima dependencia que tienen los cuerpos sensibles, y el universo en general, de los cuidados de la divinidad para evitar que se pierdan en la nada (esto se encuentra a la par de la dependencia que Berkeley alega con respecto a la constante percepción divina del mundo, para mantenerlo en el ser $)^{8}$

y, con ello, Newton (al igual que Berkeley) considera que tiene a la mano:

5. una prueba inmediata de la existencia de Dios (la percepción del mundo sensible, para los espíritus creados, es una especie de teofanía, pues ante ellos se presenta, de manera directa, la obra misma del Creador). ${ }^{9}$

\section{Antecediendo a lo anterior:}

nuestro espíritu con cualidades secundarias para que podamos percibir las ideas (esto es, los elementos inteligibles del mundo) que están en Dios:

"Pero aun cuando yo diga que vemos en Dios las cosas materiales y sensibles, es preciso tomar muy en cuenta que no digo que tenemos en Dios las sensaciones, sino sólo que es Dios quien actúa en nosotros, pues Dios conoce bien las cosas sensibles, pero no tiene sensación de ellas. Cuando percibimos algo sensible, en nuestra percepción se encuentran sensación e idea puras. La sensación es una modificación de nuestra alma y es Dios quien la causa en nosotros [las cursivas son mías] y él la puede causar aunque no la tenga, pues ve, en la idea que tiene de nuestra alma, que ella es apta para tenerla. Con respecto a la idea que se encuentra unida a la sensación, ella está en Dios y nosotros la vemos porque él tiene a bien descubrirla para nosotros y Dios une la sensación a la idea cuando los objetos están presentes a fin de que creamos que esto es así y que adoptemos los sentimientos [y las pasiones] que debemos tener con respecto a ellos." [En [39] I, III, ii, 6, p. 445.]

6 Cfr., en infra, p. 14, párrafo A).

7 En [56] he dado los argumentos que apoyan mi lectura del ocasionalismo berkeleyano, los que considero que se pueden aplicar, igualmente, a la propuesta de Newton.

8 La doctrina se encuentra ya en San Agustín; para esto, cfr., en infra, p. 29, el epígrafe de la sección $\mathrm{V}$.

9 Aquí me interesa recordar la definición que de teofanía nos da Escoto Erígena en su deslumbrante Peryphiseon: "Omnis visibilis et invisibilis creatura theophania, id est divina apparitio, potest appellari." [En [25] III §681A.] Caracterización que muy bien se aplica a las propuestas newtoniana y berkeleyana. Berkeley lo expresa en diversos lugares de su obra, pero lo hace de manera muy lúcida en su largo libro, dividido en siete diálogos, Alcifrón, del que cito un 
6. Newton hace una crítica frontal a las tesis dualista y plenista de Descartes (de manera directa, con respecto a la primera, rechaza la postulación cartesiana de la materia y, junto a esto, propone la dimensionalidad espacial como la condición necesaria de la existencia de cualquier ser, Dios incluido, por lo que tanto cuerpos - ahora no materiales, conforme a la ontología newtoniana- como espíritus serán entidades extensas en largo ancho y profundo), ${ }^{10}$

fragmento en el cual, uno de los interlocutores en el 4o. diálogo, Critón, recoge parte de la discusión anterior y ofrece la siguiente síntesis:

"CRITÓN: Algunos filósofos, convencidos de la sabiduría y del poder del Creador, a partir de la hechura y la complejidad de los cuerpos organizados y del sistema ordenado del mundo, imaginaron, sin embargo, que él dejó su sistema con todas sus partes y contenidos bien ajustados y puestos en movimiento, como un artista deja un reloj que, en adelante, continúe, por sí mismo, por algún tiempo. Pero este Lenguaje Visual [el mundo sensible berkeleyano, que su autor interpreta como un lenguaje que Dios utiliza para darnos información sobre nuestro entorno] da muestras [proves] no sólo de un Creador sino de un Gobernador providente, real e íntimamente presente y atento a todos nuestros intereses y movimientos, quien vigila nuestra conducta y cuida hasta nuestras mínimas acciones e intenciones a lo largo de todas nuestras vidas, informando, advirtiendo y dirigiendo sin cesar, de una manera muy evidente y sensible. Esto es realmente maravilloso."

Antes de la anterior intervención de Critón (amigo de Eufranor en cuya casa se llevan a cabo los diálogos —estos dos personajes representan la posición de Berkeley-), Alcifrón (el mayor de los librepensadores hospedados en casa de Eufranor) ha expresado lo siguiente, refiriéndose a la tesis de Berkeley, presentada previamente por Eufranor [en [14], 4o. diálogo, pp. 159-160]:

"AlCIFRÓN: nunca imaginé que se pudiese pretender que vemos a Dios con nuestros ojos carnales, tan directamente como vemos a cualquier ser humano y que Él hablase a nuestros sentidos en un dialecto manifiesto y claro."

Cfr. infra, nn. 47 y 48, la propuesta de Escoto Erígena acerca de la teofanía en su Periphyseon y la versión berkeleyana de la Creación, también como una presentación de las ideas de Dios, respectivamente.

10 En [50], pp. 136-137, Newton nos dice:

"4. El espacio es una disposición del ser en tanto que ser. Ningún ser existe o puede existir si no está, de alguna manera, relacionado con el espacio. Dios está en todo lugar, las mentes creadas están en algún lugar y el cuerpo está en el espacio que ocupa y lo que no está ni en todo lugar ni en algún lugar, no existe. Y, de esto, se sigue que el espacio es un efecto emanativo que surge del ser primariamente existente, porque cuando se postula algún ser, se postula el espacio. Lo mismo puede aseverarse de la duración pues ambos son afecciones del ser o atributos conforme a los cuales se denomina la cantidad de existencia de cada [ser] individual con respecto a su amplitud de presencia y su perseverancia en la existencia. Así pues, la cantidad de la existencia de Dios es eterna, en relación con la duración e infinita en relación con el espacio en el cual está presente y la cantidad de la existencia de una cosa creada es tan grande, en relación con la duración, como la duración, desde el principio de su existencia y, en relación con su amplitud de presencia, tan grande como el espacio en el que está." 
pues encuentra que, con ellas (las tesis dualista y plenista), no es posible dar una explicación coherente de:

a. la relación mente-cuerpo, ya que, conforme a las tesis cartesianas, estas sustancias son totalmente ajenas en sus propiedades ontológicas pero, además, Newton considera que la materia es algo ininteligible y, por otra parte,

b. propone la existencia de espacio vacío para poder dar una explicación correcta del movimiento de los cuerpos.

Así pues, las propuestas anticartesianas de Newton se pueden, aparentemente, resumir en lo siguiente:

I. una teoría, prima facie dualista como en Descartes, pero que consta, ya no de materia y espíritu, sino de espacio y espíritu, en la que los cuerpos son porciones de espacio modificadas por cualidades secundarias

$\mathrm{y}$

II. el espacio no es un pleno a la manera cartesiana o aristotélica anterior, sino una 3-dimensionalidad en la que no hay un continuo de cuerpos.

Una última tesis (ya señalada en 6., pero que deseo destacar) con la que Berkeley no podría estar de acuerdo, es:

tanto los cuerpos perceptibles, como los espíritus, ocupan un espacio 3-dimensional.

Ahora, en este escrito, también dedicado a un análisis del mismo texto de Newton, sostendré que en él su autor mantiene una posición panteísta enumero de inmediato las propuestas de Newton, que me permitirán llegar a esta conclusión:

(i) Newton sostiene que el espacio externo, esto es, el espacio en el que están localizados los espíritus y se mueven los cuerpos, no su espacio constitutivo [el propio de los cuerpos, de los espíritus y de Dios], es un efecto emanativo de la divinidad; ${ }^{11}$

(ii) una tesis sobre la Creación del mundo, que he anotado como la propuesta 2 de la lista anterior;

(iii) una tesis metafísica, conforme a la cual, Newton sostiene que, en la causa, el efecto debe estar contenido de manera eminente. ${ }^{12}$

Para otra caracterización del espacio como un efecto emanativo de Dios, $c f r$. infra, el texto de n. 22, en p. 15; véase, además, n. 26.

11 Véase la nota anterior.

12 En $\langle 1\rangle$, pp. 378-379, encontramos la siguiente caracterización de: 
Esta última tesis lleva a Newton a formular preguntas clásicas acerca de la relación entre el Creador y su creación, como la de inquirir cómo es que el efecto puede ser material si en el Creador no hay nada que tenga esta propiedad. ${ }^{13}$

Eminencia (lat. eminentia; ingl. eminence; franc. éminence; alem. Eminenz; ital. Eminenza). La prioridad ontológica, o sea la perfección. Eminente significa "más perfecto" y eminentemente significa "del modo más perfecto". La noción tiene su origen en la jerarquía de los seres establecida en las Instituciones teológicas de Proclo y repetida en los escritos del seudo Dionisio (cfr. especialmente De div. nom., VII). Santo Tomás señala: “Al decir 'Dios es bueno' o ‘sabio' no sólo expresamos que es causa de la sabiduría o de la bondad, sino que estas cosas preexisten en Él del modo más perfecto (eminentius)" (S. Th., I, q. 13, a. 6). En la escolástica tardía comenzó a darse el nombre de via eminentiæ a la prueba de la existencia de Dios que infiere la existencia del grado eminente o más perfecto de todos, a través de la existencia de grados diferentes de perfección en el mundo... : la expresión se encuentra en Duns Scoto, por ejemplo (Op. Ox., I, d 2, q. 2, a. 1, n. 17), quien se preocupa, por lo demás, de definir la palabra en el sentido de "lo más perfecto y más noble según su esencia y, en este sentido, precedente" (De primo principio, ed. Roche, p. 4).

La palabra fue usada por Descartes en el mismo sentido: "La piedra que no existe todavía, no puede comenzar a existir ahora si no es producida por una cosa que posee en sí, formal o eminentemente, todo lo que entra en la composición de la piedra o sea que contiene en sí las mismas cosas u otras más excelentes, que están contenidas en la piedra" ([20] III, 32; II Rép., def. IV). Y a su vez Spinoza: "Entiendo por 'eminentemente' cuando la causa contiene toda la realidad del efecto más perfectamente que el efecto mismo" (Rep. Cart. Princ. Phil., I, ax. 8)...

Véase algo relacionado con esto mismo en la nota siguiente.

13 Lo que señala Newton con esto es que está de acuerdo con la propuesta tradicional de que la causa debe tener las mismas cualidades o mejores que las que estén presentes en el efecto o, dicho de manera conversa, el conjunto de las cualidades en el efecto es un subconjunto de las cualidades en la causa.

Curiosamente, Descartes mantiene (casi) la misma tesis, con la salvedad de que no le atribuye a la divinidad que ésta sea extensa (y, con ello, material, conforme a la identificación cartesiana de extensión y materia), sino sólo que "encierre" la idea de la extensión (en esto lo sigue Malebranche; $c f r$ infra, n. 39). La propuesta cartesiana es la siguiente:

"Ahora, una cosa que pone de manifiesto la luz natural, es que debe haber, al menos, tanta realidad en la causa eficiente y total como en su efecto pues, ¿de dónde es que el efecto puede obtener su realidad si no es de la causa y cómo es que esta causa podría comunicarla, si ella misma no la tuviese? Y, de lo anterior, se sigue no solamente que la nada no podría producir cosa alguna [las cursivas son mías] sino, también, que lo que es más perfecto, es decir, que lo que contiene en sí más realidad, no puede seguirse y depender de lo menos perfecto." [En [20], p. 32.]

Berkeley parece estar más cercano al pensamiento de Newton pues, en sus Comentarios filosóficos [en [9], §625], leemos: "M.+ Una vez concedida la materia. Desafío a cualquier hombre a que pruebe que Dios no es materia."

Es interesante anotar la propuesta de Hume sobre esto mismo [en [30], IV, i, 25]: "La mente, al realizar el más cuidadoso escrutinio, nunca será posible que encuentre [sin apelar a alguna experiencia previa] el efecto en la supuesta causa, pues el efecto es totalmente diferente de la causa y, en consecuencia, nunca se le podrá descubrir en aquélla..." 
Según lo señalé en mi escrito anterior, cierto tipo de perplejidades, que aparecerán en Newton posteriormente, y la propuesta para resolverlas, figuran ya en un pensador cristiano y Padre de la Iglesia, Gregorio de Nisa (ca. 311-394), considerado "el padre de la mística occidental", quien justamente se pregunta cómo es que el mundo pueda ser material, si no hay en la causa, Dios, nada que sea material. Su respuesta es aleccionadora:

Hay una opinión acerca de la materia que no parece ser irrelevante para lo que estamos investigando y ésta es que la materia surge de lo inteligible e inmaterial, pues encontraremos que toda la materia está compuesta de cualidades y si éstas se le quitasen, por sí misma de ninguna manera se la captaría en idea. Sin embargo, cada tipo de cualidad es separada en idea del sujeto y una idea es una forma inteligible, no corpórea, de ver las cosas. Así pues, dejemos que un animal o un leño se presente ante nosotros para que lo consideremos o cualquier otra cosa que tenga una constitución corpórea. Mediante un proceso de división mental reconocemos muchas cosas ligadas con el sujeto y la idea de cada una de ellas no está mezclada con las otras cosas que estamos considerando al mismo tiempo, pues las ideas de color y de peso son diferentes y, asimismo, lo son las de cantidad y las de cualidad táctil. Así pues, la suavidad y la longitud de dos pulgadas y las otras cosas predicadas, no chocan entre sí ni con el cuerpo, en nuestra idea de ellas, pues la fórmula explicativa considerada para cada una de éstas es muy individual, conforme a lo que es y nada tiene en común con cualesquiera de las otras cualidades que conectamos con el sujeto. $\mathrm{Si}$, entonces, el color es inteligible y, así, su resistencia y su cantidad y las otras propiedades similares y si, tras eliminar cada una de éstas del sujeto se desvanece toda la idea del cuerpo, ¿qué se sigue de esto? Si encontramos que la ausencia de estas cosas causa la disolución del cuerpo, debemos suponer que

La propuesta de Hume tiene antecedentes en la doctrina de los escépticos pirrónicos, quienes se oponen, al igual que el filósofo escocés, a admitir una fuerte relación (de necesidad) entre (una posible) causa y (un supuesto) efecto. Sorabji, en [64], p. 300, presenta la siguiente cita de Galeno quien, según lo señala el mismo Sorabji, "adscribe [la opinión] a la antigua escuela empírica de medicina, la que estaba íntimamente asociada al escepticismo":

"El consecuente se descubre por experiencia y no como algo implícito (emphainomenon) en el antecedente y, por esta razón, ninguno de los doctores empíricos dicen que esto lo implica aquello sino que, más bien, dicen que esto se sigue de aquello, que esto precede a aquello y que esto acompaña a aquello." (Galeno, de Methodo Medendi 2.7.)

Nótese la muy similar formulación de Galeno y la que emplea Hume, para evitar atribuir una posible relación necesaria entre "causa" y "efecto"; tanto en el caso de Galeno como en el de Hume, sólo se habla de antecedencia y consecuencia (o simultaneidad, etc.) meramente temporales.

Newton, en la propuesta ahora comentada, como Descartes y otros pensadores de la tradición escolástica, encontraban natural la tesis a la que aquí me he referido, pues no podían explicar, de otra manera, el que una llamada causa produjese un efecto que nada tuviese en común con ella. Véase, además, el comentario de Sorabji, al texto de Gregorio de Nisa, en la nota siguiente, así como otro fragmento de Gregorio en infra, n. 18. 
su combinación es lo que genera la naturaleza material, pues una cosa no es un cuerpo si carece de figura, resistencia, extensión, peso y las demás propiedades y cada una de estas propiedades no es un cuerpo, sino que se encuentra que es alguna otra cosa cuando se la toma por separado. De manera inversa, cuando estas propiedades se combinan, ellas producen la realidad material. Ahora bien, si es inteligible la concepción y lo divino es inteligible en su naturaleza, no es extraño que estos orígenes intelectuales para la creación de los cuerpos, surjan de una naturaleza incorpórea, con la naturaleza inteligible estableciendo las propiedades inteligibles, cuya combinación trae al nacimiento la naturaleza material. $^{14}$

La propuesta interesante de Gregorio es que cada una de las cualidades que aquí menciona, por sí sola, no es un cuerpo, pero la unión de las mismas produce uno. En épocas posteriores, en la investigación de la composición de los cuerpos, se pudo constatar que la unión de dos gases ( $\mathrm{H} \mathrm{y} \mathrm{0),} \mathrm{al}$

14 Gregorio, de Hominis Opificio, cap. 24, p. 44, cols. 212-213 [las cursivas en el texto son mías]. Citado en [65], p. 53. Esta propuesta de Gregorio de Nisa da cuenta de la composición de los cuerpos sensibles, en términos de haces de cualidades, que muy bien podrían haber suscrito tanto Newton como Berkeley.

Tras la presentación de este pasaje, permítaseme citar a Sorabji, en [65], p. 52, quien nos hace una breve presentación de su autor:

"el Padre de la Iglesia, Gregorio de Nisa [...] introdujo una versión idealizada de la teoría del haz. El problema que Gregorio considera es cómo un Dios incorpóreo pudo haber creado un universo corpóreo, puesto que la causa debe ser similar al efecto. Su solución es la de decir que un cuerpo es tan sólo un haz de pensamientos y conceptos que se encontraban en la mente de Dios. Los conceptos de la lista incluyen cualidades familiares como ligero, pesado, caliente, frío, color, figura. También incluyen extensión, pero ésta no desempeña ningún papel especial [como en otras teorías] [...] Aun cuando Gregorio usa la palabra materia, a lo que con ella se refiere es sólo cuerpo y no materia prima. Se menciona un sujeto subyacente para las propiedades sólo en uno de los tres pasajes [además del que dio pie a esta nota, los otros se encuentran en infra, uno como epígrafe de la sección I y, el otro en n. 18] y, al omitirlo en otros lugares, Gregorio, posiblemente, sigue a su hermano Basilio [quien negó expresamente un sujeto subyacente] [...] En la medida en la que Gregorio menciona un sujeto subyacente, esto pudo haberle parecido suficientemente seguro luego que Plotino y Porfirio le habían privado de toda realidad..."

Pasando a otro asunto, recordemos que los biógrafos de Newton nos han señalado que éste tuvo un buen conocimiento de las doctrinas de los Padres de la Iglesia, que influyeron sobre él en sus investigaciones trinitarias y otras relacionadas con la religión, pero creo que podríamos pensar que influyeron en él incluso en cierto tipo de cuestiones ontológicas y/o cosmogónicas. Cfr. [72] p. 312, en donde Westfall señala a Gregorio de Nisa como uno de los Padres que Newton leyó y en él se encuentra la propuesta de constitución de los cuerpos en términos de haces de cualidades, que sigue Newton; pero, además, Gregorio propone dicha tesis para que se pueda dar la relación entre causa y efecto en el sentido al que Newton alude (cfr. supra, n. 13): la causa debe tener, en grado eminente, las propiedades que hayan de aparecer en el efecto. Véase, infra, en p. 13, el epígrafe de la sección I, así como la cita en n. 18, para alguna precisión mayor acerca de estos asuntos, por parte del padre de Nisa. 
combinarse en la proporción adecuada $\left(\mathrm{H}_{2} 0\right)$, producían un líquido: agua; ésta puede caracterizarse, entonces, no como una sustancia, sino como una propiedad supraveniente a la unión de hidrógeno y oxígeno. De igual manera, en el caso de Gregorio es posible decir, y esto es algo con lo que está expresamente de acuerdo Berkeley y considero que Newton lo estaría igualmente, que la materia no es una sustancia, como sí lo quería Descartes, sino que podríamos caracterizarla como una cualidad supraveniente al haz de cualidades, que es precisamente la tesis que nos presenta Gregorio de Nisa. ${ }^{15}$ Otra cosa notable es el experimento mental de eliminar todas y cada una de estas cualidades y, ¿qué nos queda? La respuesta de Gregorio es: "nada". ${ }^{16}$ Como bien lo señala Sorabji, tenemos aquí una propuesta berkeleyana trece siglos antes del nacimiento del que sería Obispo de Cloyne.

15 Véase, además, la cita en infra, n. 18.

16 Recordemos que, en la cita primeramente presentada, en supra, pp. 9-10, Gregorio nos dejó dicho que:

"Si, entonces, el color es inteligible y, así, su resistencia y su cantidad y las otras propiedades similares y si, tras eliminar cada una de éstas del sujeto se desvanece toda la idea del cuerpo, ¿qué se sigue de esto? Si encontramos que la ausencia de estas cosas causa la disolución del cuerpo, debemos suponer que su combinación es lo que genera la naturaleza material, pues una cosa no es un cuerpo si carece de figura, resistencia, extensión, peso y las demás propiedades y cada una de estas propiedades no es un cuerpo, sino que se encuentra que es alguna otra cosa cuando se la toma por separado."

Sorabji, en [65], pp. 53-55, añade el siguiente comentario:

"Dudo en traducir logos como 'idea' y en denominar idealista esta versión de la teoría del haz; yo no me apoyo en esto, sino en el discurso de pensamientos y conceptos. Es notable la analogía con la teoría de Berkeley de que los objetos son manojos de ideas y en otro lugar he argüido que el caso de Gregorio refuta la idea de que el idealismo tuvo que esperar la llegada de Berkeley. La analogía se ciñe más por lo que Berkeley dice acerca de la creación del mundo [sobre esto, véase infra, n. 48]. Una supuesta ventaja de esta teoría es que nos libra de una creación que él considera absurda, que el mundo, que convencionalmente se concibe como una sustancia corpórea que existe fuera de ( $\sin$ ) las mentes de los espíritus, la haya producido, a partir de nada, la mera voluntad de un espíritu. Por contraste, nos dice, no hay perplejidad alguna acerca de cómo un espíritu puede producir ideas. Gregorio ve ventajas comparables en su propia teoría. Además, la concesión que hace Gregorio, al hablar en un pasaje acerca de un sujeto subyacente se empata con la concesión que hace Berkeley en su obra posterior, el Siris. Él dice ahí que el viejo concepto griego de materia prima difiere del concepto de materia subyacente, que él rechaza, en ser una noción tan negativa que él no se puede permitir aceptarla. Yo considero que no está renegando de su teoría del haz sino, más bien, tratando el viejo concepto de materia prima como algo tan negativo como para ser compatible con ella.

Claro está que hay diferencias entre los dos pensadores. Conforme a Berkeley, la creación toma la forma de Dios haciendo, las ideas en su mente, perceptibles a los demás, mientras que, conforme a Gregorio, la misma consiste, al menos en parte, en que Dios aglomere en un haz las ideas. Más aún, hay una diferencia que no consideré antes. Gregorio cree que, primeramente, Dios tiene que establecer un vacío y una nada, lo que ha de entenderse como un poder para acomodar cualidades (aun cuando no se le trate como un sujeto de cualidades) 
Pero, obviamente, también es, ésta, una propuesta newtoniana, pues tanto el autor inglés, como posteriormente el irlandés, no aceptan que un cuerpo sensible sea algo más que aquello que es posible captar por los sentidos (este asunto lo traté en [59]). Berkeley nos señala lo siguiente:

Para aclarar la naturaleza, es inútil aducir cosas que no son ni evidentes a los sentidos ni inteligibles a la razón. Veamos, entonces, qué es lo que los sentidos y la experiencia nos dicen y cuáles son las razones que los apoyan. Hay dos clases supremas de cosas, cuerpo y alma. Con ayuda de los sentidos [las cursivas son mías] conocemos la cosa extensa, sólida, móvil, figurada y dotada de otras cualidades que recogen los sentidos, pero la cosa que siente, que percibe, que piensa, la conocemos mediante cierta conciencia interna. . ${ }^{17}$

[véase, a este respecto, en infra, n. 49, la propuesta de Isaac Luria, según la narra Scholem, en la que también Dios crea primero un vacío — una nada - antes de comenzar el proceso de la Creación]. Así es como entiende la aseveración en el Génesis de que, al principio, la tierra carecía de forma y era un vacío. Una tercera diferencia es que Berkeley insiste, a diferencia de Gregorio, en señalar que las ideas pueden sólo existir en una mente y aprovecha la oportunidad, que pierde Gregorio, de inferir 'la dependencia necesaria e inmediata de todas las cosas' en Dios. La propuesta de Berkeley es que las ideas pueden existir sólo mientras las contemple una mente y que, conforme a esto, el mundo físico perecería si Dios dejase de contemplar sus ideas componentes. Esta diferencia, a su vez, fluye naturalmente de una diferencia de motivación entre las dos teorías. La meta de Berkeley es la de combatir el escepticismo eliminando cualquier cosa que, como un sujeto subyacente, sea incognoscible y haciendo que el mundo físico sea algo plenamente cognoscible, a saber, ideas; por lo tanto, él tiene un fuerte interés, del que Gregorio carece, en el status de las ideas después del acto inicial de la Creación."

17 En [12], §21; en ibid., §29, al comienzo, dice: "Quítense de la idea de cuerpo, extensión, solidez y figura y nada quedará." Algo que me apresuro a añadir aquí, para evitar equívocos y confusiones, es la tesis berkeleyana de que las llamadas cualidades primarias son presentadas por las secundarias y, por esto, si se quita la extensión, en sus versiones visual y táctil, esto es, si se quitan los colores y las texturas, con ellas desaparecen extensión, solidez y figura, esto es, nos quedamos con nada. En esto, Berkeley coincide con las propuestas de Gregorio y con la de Newton, posterior a las del padre de Nisa.

Sobre esto, es posible señalar que el mismo Locke, en una obra de publicación póstuma, y Malebranche, en sus Conversations chrétiennes, señalan que son las cualidades secundarias las que nos muestran el mundo perceptible, de manera que, es por medio de las cualidades secundarias como se nos presentan las primarias; así, en el caso de Locke, se les da una importancia epistémica básica a las cualidades secundarias; asimismo, en el caso de Malebranche, las cualidades secundarias son la condición de posibilidad de nuestra percepción del mundo sensible. Los pasajes de estos autores son los siguientes; Locke nos dice: "Además del color se supone que vemos las figuras pero, en verdad, lo que percibimos cuando vemos la figura, en tanto que se la percibe por la vista, no es sino la terminación del color." [En [36] cap. XI, §“1. Of Seeing" (Sobre el ver), p. 258 (la traducción es mía).]

Malebranche, acerca de esto, nos dice:

"He aquí, pues, mi razonamiento. No es sino el color el que hace visibles los objetos; vemos y distinguimos la diversidad de los objetos únicamente por la variedad de los colores. Ahora bien, cuando vemos los cuerpos, es la idea de la extensión la que nos modifica con diversas 


\section{LA PROPUESTA DE NEWTON}

ninguna de las cosas que conectamos con el cuerpo es un cuerpo por sí mismo: no lo es la figura, el color, ni el peso, ni la extensión, ni el tamaño, ni ninguna otra de las cosas clasificadas como cualidades. Cada una de ellas es una idea, pero su combinación y unión con cada una de las otras se convierte en un cuerpo. Así pues, mientras que las cualidades que llenan el cuerpo las capta la mente y no la percepción sensorial y lo divino es inteligente, ¿qué problema tiene el ser inteligible para crear los conceptos cuya combinación entre ellos produzca, para nosotros, naturaleza corpórea? ${ }^{18}$

sensaciones de color y estaréis de acuerdo en que esta idea no se encuentra sino en Dios. Así pues, es evidente que vemos en Dios toda esta variedad de cuerpos de la que tenemos sensaciones tan diferentes, puesto que es cierto que para nada vemos los objetos en sí mismos..." [En [40] §iii, p. 76.]

Lo que en ambos casos se podría decir, siguiendo el argumento de Gregorio es que si quitamos las cualidades secundarias desaparece el objeto; pero la respuesta que podrían formular, tanto el pensador inglés como el francés es que epistémicamente se perderían los objetos, pero no así ónticamente. Sin embargo, es muy problemático saber qué es lo que se querría decir con esta respuesta y qué fundamento real tendríamos para apoyarla. Es en esta precisa coyuntura en la que tiene pleno sentido el epíteto de "ininteligible" que tanto Newton como Berkeley (e incluso Malebranche) lanzaron en contra de la postulación cartesiana de la materia.

18 El pasaje aquí citado se encuentra dentro del citado en supra, pp. 9-10, que matiza otro pasaje del mismo Gregorio:

"La creación corpórea se piensa en términos de propiedades que nada tienen en común con lo divino y, en particular, produce esta gran dificultad para la Razón, pues no se puede ver cómo lo visible proviene de lo invisible, lo sólido y resistente de lo intangible, lo limitado de lo ilimitado o, lo que por doquier está circunscrito por proporciones cuantitativamente concebidas, de lo que carece de cantidad y de magnitud y, así, para todo lo que se conecta con la naturaleza corpórea. Pero, acerca de esto, podemos decir lo siguiente: ninguna de las cosas que conectamos con el cuerpo es un cuerpo por sí mismo — no lo es la figura, el color, ni el peso, ni la extensión, ni el tamaño, ni ninguna otra de las cosas clasificadas como cualidades. Cada una de ellas es una idea, pero su combinación y unión con cada una de las otras se convierte en un cuerpo. Así pues, mientras que las cualidades que llenan el cuerpo las capta la mente y no la percepción sensorial y lo divino es inteligente, ¿qué problema tiene el ser inteligible para crear los conceptos cuya combinación entre ellos produzca, para nosotros, naturaleza corpórea?" (Gregorio, De anima et resurrectione, p. 46, cols. 124B-D; citado en [65], pp. 52-53.)

Incluso podemos aquí añadir un fragmento más de Gregorio, que complementa los anteriores:

"Siendo esto así, nadie debe sentirse ya presionado por la cuestión de la materia y de cómo y de dónde surgió. Se puede oír a la gente decir cosas como éstas: si Dios es inmaterial, ¿de dónde viene la materia? ¿Cómo pudo la cantidad provenir de la no cantidad, lo visible de lo invisible, algo con masa y tamaño limitados de lo que carece de magnitud y límites? Y lo mismo con respecto a otras características que se ven en la materia: ¿cómo o cuándo las produjo uno que no tiene nada semejante en su propia naturaleza? [...] Por su sabia y poderosa voluntad, siendo capaz de todo, estableció, para la creación de las cosas todas aquellas que constituyen la materia: ligero, pesado, denso, enrarecido, suave, resistente, fluido, seco, frío, caliente, color, 
Para tener una idea clara de la propuesta creacionista de Newton y poder referirme a ella sin problemas, me permito citar, aquí, un pasaje de su "De gravitatione. .." en el que podemos apreciar la fuerte similitud con el pasaje de Gregorio de Nisa en el epígrafe y lo próximos que ambos están de las propuestas de Berkeley con respecto a los cuerpos: ${ }^{19}$

A) Si él [Dios] ejerciese este poder [el de mover los cuerpos a voluntad y el de impedir que un cuerpo pueda penetrar cualquier espacio definido por ciertos límites] e hiciese (causase) que algún espacio, que se proyectase por encima de la tierra, como una montaña o algún otro cuerpo, fuese impenetrable a los cuerpos y, así, detuviese o reflejase la luz y todas las cosas que con él chocan, parecería imposible que no considerásemos este espacio, a partir de la evidencia de nuestros sentidos (que son nuestros únicos jueces en este asunto), como siendo, verdaderamente, un cuerpo, pues sería tangible debido a su impenetrabilidad y visible, opaco y coloreado por razón del reflejo de la luz y resonaría cuando se le golpease, debido a que el aire adyacente se movería gracias al golpe. ${ }^{20}$

Es interesante notar cuán cercanas están, la propuesta de Gregorio Niseno y la de Newton, con respecto a la concepción de lo que sea un cuerpo; según lo hemos señalado, las razones que Newton da, en su "De gravitatione..." para adoptar una propuesta como la que aquí vemos es que considera que la materia cartesiana es ininteligible y que, por tanto, no se puede tener como un sustrato de cualidades y, así, los cuerpos newtonianos serán cúmulos de cualidades (secundarias), a la manera de Gregorio, que Dios reúne en determinados lugares y que Él puede mover a voluntad. Ahora necesito otras tesis de Newton para apoyar mi alegato principal acerca de que Newton mantenía una tesis panteísta.

Citando nuevamente su "De gravitatione. . .", allí Newton nos dice:

B) Más aún, si es legítima y completa la distinción de sustancias entre pensante y extensa, Dios no contiene eminentemente la extensión en sí mismo y, por tanto, no puede crearla, por lo que Dios y la extensión serán dos sustancias separadamente completas, absolutas y poseyendo la misma importancia; pero, por el contrario, si la extensión está eminentemente contenida en Dios o en el

figura, contorno, extensión. Todos éstos son, en sí mismos, pensamientos y meros conceptos; ninguno es, por sí mismo, materia; pero, cuando se combinan, se tornan en materia." [Las cursivas son mías.] (Gregorio, in Hexæmeron, p 44, col. 69B-C; citado en [65], p. 52.)

Véase en infra, n. 39, la cita de Dionisio el seudo Areopagita, quien propone una tesis con un matiz diferente a la que aquí leemos de Gregorio.

19 Para un tratamiento más amplio de estas semejanzas, véase mi "Isaac Newton: ¿berkeleyano avant la lettre?" Cfr. supra, n. 1.

20 La cita la tomé de [50], p. 139 [las cursivas son mías]. 
ser pensante más elevado, ciertamente la idea de la extensión estará eminentemente contenida en la idea del pensamiento y, por tanto, la distinción entre estas ideas no será tan grande como para que ambas no puedan convenir a la misma sustancia creada, esto es, que tanto un cuerpo pueda pensar o que las cosas pensantes sean extensas. ${ }^{21}$

Además de lo anterior, y ahora hablando del espacio, ya Newton había señalado que:

C) Quizás ahora pueda esperarse que yo defina la extensión como sustancia, accidente o bien, como nada en absoluto; pero, esto, de ningún modo, pues la misma tiene su propia manera de existencia que no encaja ni con las sustancias ni con los accidentes. No es sustancia, por una parte, porque no es absoluta en sí misma sino que es, por así decir, un efecto emanativo de Dios y como una afección de todo ente, mientras subsiste; por otra parte, porque no está entre las afecciones propias que denotan la sustancia, a saber, las acciones, como pensamientos en la mente y movimientos en el cuerpo. . ${ }^{22}$

Nótese que Newton, al suponer que en Dios, de manera eminente, "existe" el espacio (como extensión en tres dimensiones) concluye que, por esta razón, Dios mismo es extenso, ${ }^{23}$ esto conforme al pasaje B); pero, conforme al

21 Ibid., p. 143.

22 En ibid., pp. 131-132 (latín, p. 99). Véase, en supra, n. 10, otro de los pasajes en los que Newton habla del espacio como un efecto emanativo de Dios. Por último, en ibid., p. 137, tenemos la tercera figuración de "efecto emanativo", atribuido al espacio, dentro del "De gravitatione...":

“6. Finalmente, el espacio es eterno en duración y de naturaleza inmutable porque es un efecto emanativo de un ser eterno e inmutable. Si jamás el espacio hubiese existido, en ese tiempo Dios hubiese estado en ningún lugar y, por tanto, o bien creó el espacio después, en el que él mismo no estaba o bien, lo que no repugna menos a la razón, creó su propia ubicuidad."

Lo que aquí vale la pena señalar es que, tan sólo en la cita, en el texto principal, correspondiente a esta nota, Newton usa el paliativo, "por así decir" (tanquam/como sifuera), al aplicarle al espacio el calificativo de ser un efecto emanativo de la divinidad, mas esto no sucede en las otras dos atribuciones. Recordemos, ahora, que unos años después, en 1704 y en el caso de la Óptica, Newton se refirió, en dos ocasiones al espacio como "el sensorio de Dios" e introdujo el "como si fuera" tan sólo en uno de esos casos. Véase en infra, n. 30, la historia del tanquam en el caso de la óptica.

23 Amos Funkenstein nos da los siguientes datos sobre Tertuliano, Padre de la Iglesia del siglo II, quien declara abiertamente la dimensionalidad de los cuerpos y de los espíritus, Dios incluido y a quien Newton leyó, según nos dicen sus biógrafos:

"considérese, p. ej., la defensa que hace Tertuliano (Cartago ca. 155-222)* del cuerpo de Dios: 'Nada es a menos que sea un cuerpo. Lo que sea que es, es un cuerpo de algún tipo. Nada es incorpóreo, sino lo que no es' (De anima 7: 'Nihil enim, si non corpus. Omne quod est, corpus est sui generis: nihil est incorporale, nisi quod non est'). En otro pasaje, leemos: '¿Quién puede 
C), al ser, el espacio, un efecto emanativo de la divinidad (además de ser una afección de todo ente, mientras subsiste), el espacio mismo es Dios o algo necesariamente unido a Dios y, además, es una condición de posibilidad de la existencia de todos los seres. ${ }^{24}$ Conforme a estos pasajes tenemos, entonces, que parece que Newton postula la existencia de dos tipos de espacio: uno, el espacio interno o el espacio propio de cuerpos y espíritus y, el otro, el espacio externo, el espacio dentro del cual se mueven los cuerpos (y, ¿también los espíritus?). ${ }^{25}$

\section{NOCIONES DE ESPACIO EN NEWTON}

Lleno de mí, sitiado en mi epidermis por un dios inasible que me ahoga...

José Gorostiza: "Muerte sin fin"

Aquí, me parece que es pertinente hacer la siguiente observación. Es difícil saber cómo interpretar la relación entre el espacio newtoniano y Dios, pues Newton nos dice que todo ente, tan sólo por el hecho de ser, debe ocupar lugar y tiempo; en caso de no hacerlo, ese supuesto ente no existe. ${ }^{26}$ Parece

negar que Dios sea un cuerpo, aun cuando sea espíritu? El espíritu también es un cuerpo a su manera' (Adversus Praxen 7: 'Quis enim negaverit, deum corpus esse, etsi deus spiritus est? Spiritus enim corpus sui generis in sua effigie')...

* Apologista cristiano, el primero de los escritores cristianos en lengua latina. Pagano converso, ejerció en África del Norte un verdadero magisterio doctrinal. Autor de la Apologética y del Adversus marcionem; su ascetismo lo hizo desviarse hacia la herejía montanista [por Montanus o Montano, sacerdote frigio, de Cibeles, convertido al cristianismo, fundador del montanismo (siglo II). Pretendió ser la voz del Espíritu Santo venido a completar la Revelación de Jesucristo y, conforme a esto, desarrolló una doctrina, conocida como 'herejía frigia', que profetizaba la inminencia del fin del mundo.]. Tuvo una gran influencia en la formación de la lengua teológica latina." [En [26] p. 156.]

24 De acuerdo con el pasaje C) antes citado, así como al pasaje citado en supra, n. 10, "El espacio es una disposición del ser en tanto que ser. Ningún ser existe o puede existir si no está, de alguna manera, relacionado con el espacio... ", cfr. en [8], cap. 2, las secciones dedicadas a Patrizi y se verá la profunda similitud de las tesis del autor inglés con las del autor de Cherso; cfr., además, infra, n. 26.

25 Newton, al hablarnos del espacio de los seres, en tanto que condición necesaria de su ser existentes, nos habla de lo que Edward Grant denomina espacio interno, esto es, el espacio en tanto que característica del objeto dimensional, a diferencia del espacio externo, esto es, del espacio como algo ajeno a los seres, un espacio a través del cual éstos se mueven. Los seres "llevan consigo" su espacio interno y se mueven a través del espacio externo. Sobre esto, véase [29], pp. 14-19.

${ }^{26}$ Cfr. supra, n. 10 y el texto correspondiente a las nn. 22 y 24. Francesco Patrizi [en [54], 72/225] dice, hablando del espacio: "es necesario que este ser sea anterior a todas las otras cosas; cuando está presente, todas las otras cosas pueden ser; cuando está ausente, son destruidas (quo posito, alia poni possunt omnia: quo ablato, alia omnia tollantur)" y, un poco 
que está claro que el espacio, en tanto que "efecto emanativo de Dios", se refiere al espacio externo pues, según nos dice Newton, los seres, tan sólo por el hecho de ser son espaciales, esto es, son espaciales per se en largo, ancho y profundo y, por esta razón, ocupan una 3-dimensión y ésta estará en el espacio en tanto que emanación. Pero, este espacio, en tanto que emanación de Dios:

1. ¿es algo separado y ajeno a la divinidad? O, más bien, ¿es en este espacio en el que Dios está omnipresente?

Ciertamente no es propio decir que Dios esté omnipresente en su propio ser, esto es, en su espacio interno, pues Él es ese espacio y, entonces, será el emanado de Él el que ocupe en plenitud y el que los seres creados ocuparán en la medida de sus extensiones. De aquí surge la siguiente inquietud:

2. si Dios ocupa la infinita totalidad del espacio, ¿̇uál es el sentido que pueda tener suponer un espacio que "envuelve" completamente a Dios o del cual, sus dimensiones, se interpenetran con las dimensiones divinas?

3. ¿Se puede distinguir el espacio interno de la divinidad del espacio externo que supuestamente "ocupa"? Realmente, ¿“ocupa" Dios algún espacio?

Y, de los seres creados:

4. ¿podrá decirse que están fuera de Dios si existen en el espacio que está pleno de Dios?

Si la respuesta es que no es posible que estén fuera de Dios, porque Dios, en tanto que infinitamente espacial lo ocupa todo y, así, nada puede estar fuera de Él, entonces, siguiendo la doctrina paulina podríamos decir, de

más adelante, continúa: “Todas las cosas, sean éstas corpóreas o incorpóreas, si no están en alguna parte, en ninguna están. Si en ninguna están, ni siquiera existen. Si no existen, nada son. Si nada son, no existirán ni las almas, ni las naturalezas, ni las cualidades, ni las formas, ni los cuerpos." En un manuscrito de principios de la década de 1690 [posterior al escrito que aquí nos ocupa y en el que figura la propuesta que presento a continuación —cfr., supra, n. 10], que J.E. Mc Guire denominó "Tempus et Locus", Newton afirma lo siguiente, completamente dentro del marco de la propuesta de Patrizi:

"Tempus et Locus sunt omnium rerum affectiones sine quibus nihil omnino potest existere. In tempore sunt omnia quoad durationem existentiæ \& in loco quoad amplitudinem præsentiæ. Et quod nunquam nusquam est, id in rerum natura non est. ["El tiempo y el lugar son afecciones comunes de todas las cosas, sin las que ninguna cosa que sea puede existir. Todas las cosas están en el tiempo con respecto a la duración de existencia y en el lugar con respecto a la amplitud de presencia. Y lo que nunca es ni está en lugar alguno, no está en la naturaleza de las cosas."] En [45], p. 116 (latín) y p. 117 (inglés). 
manera literal, que "En Él vivimos, nos movemos y tenemos nuestro ser", ${ }^{27}$ lo que significa que no parece que podamos decir que haya algo fuera de Dios. $^{28}$

Si lo anterior es así, entonces es difícil ver cómo puedan distinguirse los espacios interno y externo de la divinidad y quizás, debido a esto, es que Newton habló del espacio como del sensorio de Dios, ${ }^{29}$ cuando debería haber

27 En Hechos XVII, 28.

28 Berkeley parece haber entendido a Newton o a los newtonianos de esta manera y así nos dice:

"pero, la principal ventaja que surge de esto [de rechazar la tesis newtoniana del espacio absoluto] es que nos liberamos de ese peligroso dilema, al que se imaginan reducidos muchos que han dedicado sus pensamientos a este tema, a saber, pensar que el espacio real o bien es Dios o bien que hay algo, además de Dios, que es eterno, increado, infinito, invisible, inmutable. Nociones, ambas, que pueden, con justicia considerarse perniciosas y absurdas. Es cierto que no pocos teólogos así como filósofos de gran distinción han concluido, debido a las dificultades que han encontrado para concebir o bien límites o la aniquilación del espacio, que éste debe ser divino y, recientemente, algunos se han propuesto, en particular, mostrar que los atributos incomunicables de Dios concuerdan con él. .. " [En [10] §117.]

En una ocasión y lugar diferentes, el filósofo irlandés nos dejó dicho lo siguiente:

"2. Con respecto al espacio. No tengo ninguna noción de otro que no sea relativo. Sé que algunos filósofos recientes le han atribuido extensión a Dios y en especial los matemáticos, uno de los cuales, en un tratado, De spatio reali [el autor de este escrito fue Joseph Raphson (1648-1715), quien lo publica en 1702, como un apéndice a un libro suyo de Análisis; para ver algo más sobre este autor, cfr. [8], cap. 6], pretende encontrar quince de los atributos incomunicables de Dios en el Espacio. Pero me parece que, por ser todos ellos negativos, muy bien podría haberlos hallado en la Nada y que tan justamente podría haber inferido, que el Espacio es inanimado, increado, indivisible, etc., tanto que es Nada como que es Dios." [En [13] 292/248.]

Sobre esto mismo, cfr. $\langle 7\rangle$ V, pp. 126-128 (Siris $\S \S 269-271$ ).

29 En la primera edición de la Óptica de 1704, Newton escribió lo siguiente:

“¿Cómo es que el movimiento del cuerpo se sigue de la voluntad y dónde está el instinto en los animales? ¿No es, el espacio infinito, el Sensorio de un Ser [Annon Spatium Universum, Sensorium est Entis] incorpóreo, viviente e inteligente, quien ve íntimamente las cosas mismas y a fondo las percibe y las comprende plenamente por su inmediata presencia ante sí mismo..." (Citado en [71], p. 647.)

Luego Westfall hace el siguiente comentario:

"En el último momento; realmente, después del último momento, Newton decidió que ciertamente había sido muy audaz. Él intentó recoger toda la edición [de la Óptica] y, de las copias en las que pudo poner mano, cortó la página pertinente y le pegó una nueva en la que afirmaba, no que el espacio infinito es el sensorio de Dios, sino que 'hay un Ser incorpóreo, viviente, inteligente, omnipresente quien, en el Espacio infinito, por así decir, en su Sensorio [tanquam Sensorio suo] ve íntimamente las cosas mismas...'. Lamentablemente, él no logró alterar todas las copias y una pudo llegarle a Leibniz, quien no se contuvo para ridiculizar el concepto del espacio como el sensorio de Dios." [Ibid., pp. 647-648.] 
dicho, más bien, que Su espacialidad es la que le permite "ver internamente las cosas mismas en su más profunda intimidad". ${ }^{30}$

Ahora me interesa reforzar mi alegato anterior y recordar la manera como Newton presentó su idea de la Creación. En ella, sugirió que Dios podría escoger alguna porción de espacio — del que se presenta como "un efecto emanativo de la divinidad" - y dotarla de cualidades sensibles y que, posteriormente podría mover ésa, Su creación, la que claramente se podría considerar un cuerpo. ${ }^{31}$ Pero recordemos, también, que Newton no concede que el espacio pueda moverse ${ }^{32}$ por lo que, lo que se movería, sería el haz de cualidades que Dios unió y, por ello, parece que podemos decir que el espacio propio de ese cuerpo o su espacio interno, no es diferente del espacio que surge como "un efecto emanativo de la divinidad" y, si esto es así, el espacio interno o, el espacio propio de un cuerpo, no será algo que el cuerpo lleve consigo, ${ }^{33}$ sino que tendrá que definirse siempre de manera relativa, con respecto a la porción del espacio externo que ocupe el haz de cualidades en un tiempo $t$. $\mathrm{O}$, dicho de una manera más precisa: "el espacio interno de un cuerpo $c$, en un tiempo $t$, será aquella porción del espacio externo que el haz de cualidades que componen $c$, ocupe en $t$ ". ${ }^{34}$

30 En las ediciones posteriores a la de 1704, en las interrogantes (queries) 28 y 31, figura, en la primera, la expresión "como si fuera" [véase la nota anterior], pero esto no sucede en la segunda [las cursivas en las citas son mías]:

"QU. 28 Y una vez correctamente resueltas estas cosas, ¿no muestran los Fenómenos que hay un Ser incorpóreo, viviente, inteligente, omnipresente quien, en el Espacio infinito, como si fuera (tanquam) en su Sensorio, ve íntimamente las cosas mismas y las percibe a fondo y las comprende plenamente por su inmediata presencia ante sí..."

"Qu. 31 y el instinto de los brutos y de los insectos no puede ser efecto de nada más que de la Sabiduría y de la Habilidad de un Agente por siempre vivo y poderoso quien, al estar en todo lugar, es más capaz, por su Voluntad, de mover los cuerpos dentro de su uniforme Sensorio ilimitado y, así. .. " [En [52], pp. 370 y 403.]

Cfr. en supra, n. 22, la historia del tanquam, ahora referido a la expresión "efecto emanativo". Teniendo en cuenta estos deslices lingüísticos, uno estaría tentado (yo lo estoy) a concluir que Newton consideraba el espacio algo fuertemente o necesariamente ligado a Dios y no como algún elemento externo a la divinidad.

31 Cfr. supra, p. 14, párrafo A).

32 En [50], p. 136, figura una formulación de esta propuesta que luego, de manera más compacta, reaparece en sus Principia; presento, aquí, esta última:

"Ut ordo partium temporis est immutabilis, sic etiam ordo partium spatii. Moveantur hæ de locis suis, \& movebuntur (ut ita dicam) de seipsis". ("Así como es inmutable el orden de las partes del tiempo, también lo es el orden de las partes del espacio. Supóngase que esas partes se sacaran de sus lugares y (si se me permite la expresión) se sacarían de sí mismas.") [En 51], p. 48/[51'] I, p. 8; además, cfr., en [8], cap. 2, las secciones dedicadas a Filópono y a Patrizi.]

33 Cfr. supra, n. 25, la caracterización de Grant de espacio interno.

34 En [50], p. 139, luego de haber propuesto su tesis de la creación, en la que se dota una porción de espacio con cualidades sensibles, Newton sigue diciendo: 
La conclusión a la que hasta ahora he llegado es que, con respecto a los cuerpos, no podemos hablar de un espacio interno (como algo propio del cuerpo) y diferente de un espacio externo (el espacio a través del cual se mueve el cuerpo); sin embargo, si el haz de cualidades permanece constante, sobre él se pueden llevar a cabo una serie de operaciones que nos permitirán conocer diversas propiedades del mismo, entre otras, sus propiedades métricas; se podrá, igualmente, compararlo con otros haces de cualidades y ver similitudes y diferencias, etc. Esto es, se podrán llevar a cabo todas las operaciones que es posible efectuar en los cuerpos físicos, pues, en un sentido preciso, los cuerpos que consideran Newton y Descartes, externamente no difieren para nada, en el sentido de que, en ambos casos, se presentan con las mismas cualidades sensibles. Sin embargo, desde el punto de vista del marco teórico de cada uno de estos pensadores, los cuerpos son radicalmente diferentes y, por esto, podrá Newton obtener conclusiones muy distintas de las de Descartes con respecto al mundo que nos rodea. Lo que aquí es importante subrayar es que la propuesta de Newton acerca de lo que sean los cuerpos está formulada de manera tal que, acerca de ellos, se puedan formular hipótesis avaladas por la experiencia, llevar a cabo predicciones y retrodicciones precisas acerca de su comportamiento, etc.; esto es, llevar a cabo un programa de investigación y descubrimiento en filosofía natural.

Con respecto a los espíritus, ¿se podría concluir algo parecido, acerca de la identidad del espacio en tanto que interno o externo y caracterizar el espacio interno sólo de manera relacional?

Creo que lo anterior se podría hacer con respecto, tan sólo, a los espíritus finitos, pero no con respecto a Dios. Si esto se pudiese concluir, entonces se podría alegar algo acerca de la inutilidad de hablar de un espacio que Dios "ocupase" y, de igual manera, tal como lo señalé unos renglones atrás, Pablo estaría literalmente justificado y, para darle más peso a esta conclusión, me apoyaré en lo que, algunos años después de escribir su "De gravitatione..." e incluso después de haber publicado la primera edición, de su obra magna, nos dice el mismo Newton, en el "Escolio general" de sus Principia, en su segunda edición de 1713:

Dios es el mismo Dios siempre y por doquier. Él es omnipresente, no sólo virtualmente, sino también sustancialmente; pues lo virtual no puede subsistir sin la sustancia. En él están contenidas todas las cosas y se mueven; empero, ninguna

"Si, además, podemos imaginar que esa impenetrabilidad no se mantiene siempre en la misma parte del espacio, pero puede transferirse de aquí para allá conforme a ciertas leyes, sin embargo, de tal manera que no cambien la cantidad y la figura de ese espacio impenetrable, no habrá ninguna propiedad del cuerpo que esto no la posea..." 
afecta a la otra; Dios nada sufre por el movimiento de las cosas; las cosas no encuentran ninguna resistencia por la omnipresencia de Dios. ${ }^{35}$

\section{SOBRE LA RELACIÓN CAUSA-EFECTO Y EL PANTEÍSMO}

[Dios] Es verdaderamente Rey del universo: todas las cosas dependen de Él, que es su causa, principio y fin. Él es, como dice la Escritura, "todo en todas las cosas" y ciertamente merece la alabanza como creador y Fundamento de todas las cosas, su perfeccionador, conservador, guardián y morada. ${ }^{36}$

Ahora, volviendo al párrafo B) ${ }^{37}$ y teniendo en cuenta la creación del mundo que Newton sugiere en el texto que comentamos, ${ }^{38}$ entonces él tendría que aceptar que Dios es todo aquello que en Él existe de manera eminente y, así, Dios se haría uno e idéntico con su "creación", pues en Él toda ella existiría de manera eminente por lo que, con respecto a la misma, no podría tener distancia alguna. $\mathrm{Y}$, ciertamente, la dependencia de sus criaturas con respecto a su Creador sería absoluta, ya que ellas serían Él mismo. De esta manera, como Newton concluye, no habría extrañeza alguna en suponer un cuerpo pensante o el espíritu extenso; no habría forma de distinguir una de otra sustancia; entonces, vendríamos a tener sólo aspectos diferentes de uno y el mismo ser y, por esto, tampoco habría ningún problema para pensar en la interacción entre cuerpo-espíritu y espíritu-cuerpo, pues ambas entidades no serían ajenas ontológicamente como sucedía conforme a la propuesta de Descartes.

Malebranche hace una interpretación similar a la de Newton, con respecto al ser eminente de las cosas en "la mente" del Creador, pero se cuida de obtener la misma conclusión que lo conduciría al panteísmo. Para el Oratoriano, Dios es cartesianamente no extenso (propuesta absurda e ininteligible para Newton) y, sin embargo, en Él "están" todas las verdades acerca de la extensión (esto es, en Dios, la extensión figura como idea, mas no como entidad material), ${ }^{39}$ Él la comprende plenamente y nos muestra todas las verdades acerca de ella, aun cuando nuestro entendimiento finito

35 En [51] III, "Escolio general" a Prop. XLII, Prob. XXII, p. 545.

36 En [23], cap. 1, [596C], p. 277. Acerca de la expresión "Todo en todas las cosas", cfr. infra, n. 49, in fine, el origen de esta expresión y el uso que de ella hace Scholem atribuyéndosela a Isaac Luria.

37 En supra, pp. 14-15.

38 En [50], p. 148; cfr. mi observación en supra, p. 14, inciso A); por otra parte, este pasaje lo comento en [59], §1, pp. 201-204.

39 Con esto rechaza, entonces, la tesis de la relación estrecha entre la causa y el efecto que hemos considerado en el caso de Newton y de Gregorio de Nisa. En el Recueil de toutes les réponses a monsieur Arnauld (Compilación de todas las respuesta al señor Arnauld), [41] VI, p. 242, Malebranche presenta claramente su propuesta: 
nunca las podrá captar en su plenitud..$^{40}$ De esta manera, para el cartesiano Malebranche, una cosa es ser extenso y otra, por completo diferente, es comprender lo que sea la extensión, lo que, al parecer, Newton confunde: Dios comprende plenamente lo que es la extensión (y, por esto, podemos decir — hablando con propiedad cartesiana- que la extensión —o, mejor, la forma separada de la extensión- existe objetivamente en Dios y esto de manera eminente) sin que, por ello, Dios sea (o tenga que ser) extenso. ${ }^{41}$

"En mi respuesta al Sr. de la Ville mantuve, siguiendo a san Agustín, que la materia no era sino extensión en largo, ancho y profundo, pero jamás pensé que la idea de largo, ancho y profundo fuese larga, ancha y profunda o que el cuerpo inteligible fuese material, mayor en un espacio mayor que en uno menor..."

Dionisio, el seudo Areopagita, tiene lo siguiente que decir acerca de este mismo tema:

"La Sabiduría divina conoce todas las cosas conociéndose a sí misma. Conoce inmaterialmente las cosas materiales, indivisiblemente las cosas divisibles, unitariamente las múltiples. Porque todo lo conoce y lo produce con un solo acto. Porque es cierto que Dios, como Causa única y universal, confiere la existencia a todos los seres, por la misma razón conocerá todo ser, pues procede de Él y preexiste en Él." [En [23], cap. 7 [869B], p. 338.]

Cfr. en supra, n. 18, las propuestas de Gregorio de Nisa con respecto a la relación entre Dios y sus criaturas, lo que tiene una fuerte relación con la cita que aquí presentamos de Dionisio.

Volviendo ahora a Malebranche, quien ha formulado una muy convincente argumentación, para mostrar que este autor no es panteísta porque difiere de Spinoza precisamente en que el primero mantiene una distancia entre Dios y su creación y sostiene que en Dios se encuentran sólo las ideas, pero no los entes finitos materiales, en tanto que Spinoza mantiene una propuesta muy similar a la que Newton pretende achacarle a Descartes, es Syliane Charles, en su artículo Lidée de l'étendue chez Malebranche et Spinoza, ou porquoi Malebranche n'etait pas panthéiste (en parte inédito).

40 En la primera de sus Trois lettres de l'auteur de la Recherche de la verité... (Tres cartas del autor de la Investigación de la verdad... ), como respuesta a la objeción de Arnauld, Malebranche nos dice:

"IX. Es verdad, se dirá, las figuras geométricas, las criaturas, todas las cosas están en Dios, pero idealmente y, para nada, de otra manera. Estoy de acuerdo, yo respondería, pero siempre que este idealmente señale que ellas están ahí efectivamente y de manera muy distinta de como están en mí, que no soy la luz para mí mismo; siempre que este idealmente señale suficientemente que la sustancia divina es representante de todas las cosas, ante todas las inteligencias, puesto que, efectivamente, ella encierra, de manera inteligible, todos los seres, tanto creados como posibles, a causa de que ellos tienen participaciones infinitamente limitadas, no dirá sino lo que yo digo y lo que dice santo Tomás en los lugares a los que acabo de remitir... " [En [41] VI, p. 209.]

41 Me parece que, claramente, podemos decir que lo que Newton propone, en el pasaje que comento, es una versión del argumento anselmiano, conforme al cual, una entidad con todas las perfecciones en un grado supremo no puede no existir; así pues, iDios existe! El argumento, Anselmo de Canterbury (1033-1109) lo usó, como bien se sabe, para probar la existencia de Dios y, como también se sabe, dicho argumento ha recibido, a partir de Kant (y desde antes) innumerables críticas. Aquí no me detendré a presentarlas, sino sólo a considerar la inferencia newtoniana. 
Arnauld es quien le achaca a Malebranche la misma confusión que aquí le atribuyo a Newton: porque en Dios "existe" la extensión (en tres dimensiones, largo, ancho y profundo), entonces Dios es extenso, esto es (siguiendo la tesis de Descartes), material. La propuesta malebranchiana la encuentra Arnauld en el famoso capítulo 6 de la segunda parte del libro 3 de la Investigación de la verdad, que lleva por título, "Que vemos todas las cosas en Dios" y le achaca al Oratoriano una tesis similar a la de Gassendi, que el autor jansenista presenta de la siguiente manera:

Ellos (los hombres) han recibido, además, este otro principio como incontestable, que el alma no ve los cuerpos sino mediante imágenes o especies que los representan y han extraído, de esto, diferentes conclusiones, según su diversa manera de filosofar y algunas son muy desagradables, pues he aquí cómo razona el Sr. Gassendi o, más bien, aquellos de quienes propone los pensamientos como objeciones que él desea que responda el Sr. Descartes: Nuestra alma no conoce los cuerpos sino por ideas que los representan; ahora bien, estas ideas no podrían representar cosas materiales y extensas si ellas mismas no fuesen materiales y extensas; así pues, ellas lo son. Pero, a fin de que le sirvan al alma para conocer los cuerpos, es preciso que estén presentes al alma, es decir, que el alma las reciba. Ahora bien, lo que es extenso no puede ser recibido sino en una cosa extensa; así pues, es preciso que el alma sea extensa y, en consecuencia, corpórea. Por condenable que sea esta conclusión, no veo que sea fácil no admitirla, si se admiten los principios, lo que debe hacernos juzgar que estos principios no podrían sino ser falsos. ${ }^{42}$

El buen Oratoriano se rebeló en contra de esta interpretación de su doctrina y, por esto, surgió una larga polémica entre él y el jansenista Arnauld.

En el caso del padre del Oratorio, la presencia eminentísima en Dios, en idea, del cuerpo o de la extensión, no hace de Dios un ser corpóreo o extenso y esto, el que Dios no sea lo uno o lo otro, no le impide crear entes con esas características. La tesis neoplatónica extensionista, propuesta por Henry More, es la que Newton acepta y propone; esta misma tesis, según

Aparentemente, la propuesta de Newton es la de mantener que si $\alpha$ está presente en la mente divina, con su máximo grado de perfección (y, al estar en Dios no podría ser de otra manera), entonces $\alpha$ debe existir (de la manera que le es propia), pues es más perfecta una entidad existente que una entidad tan sólo concebida; sin embargo, manteniendo una tesis diferente de la relación causal, como la que proponen Descartes y Malebranche, no se sigue que quien concibe deba tener las propiedades de la cosa concebida, pero esta última parece ser la conclusión de Newton.

42 En [6], cap. IV, pp. 35-36. Obviamente, la conclusión de que, por ser extensa el alma ha de ser material, es una inferencia cartesiana, por la identificación espacio-materia, pero no sería aceptable para Newton, ya que él ha rechazado tal identidad y, con ello, la ininteligible materia cartesiana y, por tanto, ningún espíritu extenso y menos aún el espíritu supremo, padecen de las imperfecciones atribuibles a la materia. 
ya lo señalé en otro lugar, ${ }^{43}$ es la misma que, en el siglo xvI, propusiera Francesco Patrizi, quien igualmente señala que la extensión dimensional es una condición de posibilidad de existencia de los entes. ${ }^{44}$

Además, he citado los pasajes de Gregorio de Nisa, quien también estaba preocupado por el aspecto materia como posible atributo de Dios y, según nos lo señala Sorabji, ${ }^{45}$ el padre de la Iglesia sigue la propuesta de Plotino (205-270), a través de Porfirio y elimina la materia a favor de un haz de cualidades secundarias.

\section{ALGUNAS CONSIDERACIONES SOBRE “CREATIO EX NIHILO” Y PANTEÍSMO}

Aquí quiero detenerme a fin de intentar obtener alguna claridad acerca de lo que quiera decir la frase creatio ex nihilo, ya que, conforme a la ortodoxia sobre la divinidad, fuera de ésta, nada hay, pues la divinidad lo llena o, más bien, lo contiene todo. Así pues, en cierto sentido claro de la frase, no es posible que haya una creatio ex nihilo cuando el universo todo y más allá, es un plenum de Dios. Pero, entonces, ipodemos darle un sentido a esa nada, que la haga diferente de la esencia divina o, dicho de otra manera, podemos encontrar una forma de apartar a Dios de su Creación, de tal manera que ésta pueda decirse que es algo que "está fuera de la divina esencia, esto es, de la plenitud del ser de Dios"? ¿Puede Dios emanar algo fuera de su esencia que lo abarca todo?

Difícilmente se podrá decir que Dios crea "fuera de sí" el mundo pues, ¿qué hay fuera de Dios? ¿Es posible, siquiera, entender qué sea a lo que uno se refiere con esta expresión? Si Dios lo llena todo, entonces no hay nada fuera de la plena y total esencia de la divinidad, por lo que el panteísmo se hace presente de inmediato. ${ }^{46}$

43 En [8], cap. 2, $\S 2.4$.

44 Cfr., en supra, n. 26, una cita pertinente de Patrizi al respecto.

45 Cfr. supra, n. 14.

46 Escoto Erígena, en el Periphyseon [[25] I, 72, [517A-C], p. 115], hace decir al "Alumnus" lo siguiente, que el "Nutritor" acepta:

“A: Yo no creería que hubiese algo más aparte de Él [Dios] y fuera de Él; pues, en Él están todas las cosas y, fuera de Él, nada hay. Y yo no sería tan audaz como para conceder algún accidente en Él pues, de esta manera, Él no es simple sino un compuesto de esencia y accidentes pues, si se considera que otra cosa que no fuese Él mismo (estuviese) con Él entonces, ciertamente, Él no sería ni infinito ni simple..."

Véase en infra, n. 49, la presentación que hace Scholem de los cuestionamientos de Isaac Luria acerca de una Creación de la nada; éstos están fuertemente emparentados con lo que aquí propone Escoto Erígena.

En Sobre la naturaleza de las cosas, Lucrecio comienza la exposición de su doctrina a Memio (amigo y discípulo del autor a quien éste le dedica el poema), en I, 146-214, rechazando una 
Un camino, mediante el cual se trató de dar cuenta de la creatio ex nihilo, está presente en el asombroso Periphyseon (traducido al latín como De divisione naturæ o De la división de la naturaleza), gran libro de Juan Escoto Erígena ( $c a$. 810-877), filósofo y teólogo irlandés, influido por el neoplatonismo, maestro en la corte de Carlos II "el Calvo" (823-877), quien da un giro epistémico a la interpretación de la nada y la hace ser la esencia íntima de la divinidad, que va más allá de nuestras capacidades intelectivas y será de ese ser más profundo de Dios, de esa nada para nuestra captación e intelección, de la que Dios crea el mundo. ${ }^{47}$ En este caso, sin embargo, el monje irlandés no se salvó de ser tachado de panteísta y su obra máxima, el Periphyseon, la condena el concilio de París en el año de 1210, a casi 340 años de la muerte del autor. ${ }^{48}$

divina creatio ex nihilo; a Lucrecio la propuesta le parece absurda, da sus razones para esto y, ciertamente, el discurso se complementa líneas después, 215-264, en las que Lucrecio señala que tampoco es posible la aniquilación, esto es, la desaparición de las cosas en la nada: las cosas compuestas pueden destruirse, pero los principios que las componen, los átomos, son indestructibles. Así, el universo atomista es eterno, esto es, increado e imperecedero. En su gran poema, Lucrecio le dice a Memio:

“(146) Este terror del ánimo y estas tinieblas [Lucrecio alude a lo que ha dicho en las líneas anteriores sobre la pobreza del latín para expresar adecuadamente muchas de las cosas que él desea comunicar] es preciso que los disipen no los rayos del sol ni los lucientes dardos del día sino la visión y la explicación de la naturaleza. Desde nuestro punto de vista, un principio sustenta toda la urdimbre: que ninguna cosa se engendra jamás de la nada por acción divina pues la religión de tal manera inhibe a todos los mortales, que dicen suceder por potestad divina todas aquellas cosas del cielo y de la tierra cuyas causas no pueden explicarse. Por eso, después que hayamos visto que nada puede crearse de la nada, tendremos una perspectiva más clara y entonces, veremos cómo se crea cada cosa y de qué modo todo sucede sin obra de los dioses (158)." [En [38], pp. 9-10.]

47 El siguiente pasaje del Periphyseon [[25] III, 17 [678D-679A], p. 305] es ilustrativo de la propuesta panteísta de Escoto Erígena, en el que, hablando de Dios, nos dice:

"y, en tanto es eterno, no deja de ser hecho y, al ser hecho no deja de ser eterno y, a partir de sí mismo se hace a sí mismo, pues no requiere de ninguna otra materia que no sea sí mismo en la cual hacerse a sí mismo. De otra manera, parecería que es impotente e imperfecto en sí mismo si fuese a recibir de alguna otra fuente una ayuda para su manifestación y perfección. Así pues, es de Sí mismo que Dios toma la ocasión de Sus teofanías, esto es, de las divinas apariciones, puesto que todas las cosas son a partir de Él y a través de Él y en Él y para Él y, por tanto, incluso esa materia de la que se lee que Él hizo el mundo, es a partir de Él y en Él y Él está en ella en tanto que se entiende que tiene ser".

Cfr. en supra, n. 9, algo más acerca de teofanías.

48 Véase la p. 20 de la "Introducción" a $\langle 11\rangle$, en donde se habla de la influencia que Dionisio, el seudo Areopagita, tuvo en Escoto Erígena.

Pasando ahora a otro tema relacionado, en una carta de Berkeley a su amigo Percival (fechada en Trinity College el 6/IX/1710, antes de la publicación de los Tres diálogos entre Hylas y Filonús, el que sería obispo de Cloyne presenta su versión de la Creación; cfr., [11] III diál., pp. 251-252, en donde Berkeley publica su versión de la creación, la cual sigue muy 
Un pensador que intentó dar una versión ontológica de la creatio ex nihilo, fue Isaac Luria (1534-1572) ${ }^{49}$ quien, en su teoría del tsimtsum, se propone

de cerca la que aquí presento como la versión que le envió a Percival), quien anteriormente le había comunicado una duda de su esposa con respecto a la doctrina de la Creación del primero, dentro del esquema inmaterialista; Berkeley le responde lo siguiente [En $\langle 7\rangle$ VIII, pp. 37-38.]

"Por lo que toca a la objeción de tu señora, me siento muy honrado por ella y he de reconocer que es una gran desgracia, en caso de que cualquier prejuicio en contra de mis nociones debilite los buenos pensamientos que, según dices, ella tiene hacia mí, así que no seré poco cuidadoso en satisfacerla con respecto a su observación acerca de la consistencia de la Creación, con la doctrina en mi libro. Para llevar a cabo esto, debo pedirte que le informes a su Señoría, que yo no niego la existencia de ninguna de esas cosas sensibles que Moisés dice que fueron creadas por Dios. Ellas existían desde toda la eternidad en el intelecto divino y luego se hicieron perceptibles (esto es, fueron creadas) de la misma manera y en el orden que se describe en el Génesis, pues considero que la Creación pertenece a las cosas sólo con respecto a los seres finitos, al no haber nada nuevo en Dios. Por tanto, se sigue que el acto de la creación consiste en la voluntad de Dios de que esas cosas, que sólo Él conocía, hayan de percibirlas otros espíritus. Ahora bien, tanto la razón como las escrituras nos aseguran que hay otros espíritus (como ángeles de diversos órdenes, etc.) además del hombre, que es posible que pudiesen haber percibido este mundo visible a medida que se fue exhibiendo sucesivamente ante ellos antes de la creación del hombre. Además, para concordar con la versión mosáica de la creación, basta con suponer que un hombre, en el caso de que entonces fuese creado y que existiese en la época del caos, pudiese haber percibido todas las cosas que se formaban a partir de éste en el mismo orden establecido en las Escrituras, lo que de ninguna manera va en contra de nuestros principios. No sé si me expreso con la suficiente claridad como para que me entienda una dama que no ha leído mi libro..."

Es claro que Berkeley coincide con la propuesta de su coterráneo (Juan Escoto Erígena), al mantener que la nada es epistémica, esto es, hay que entenderla como referida a nuestro desconocimiento de las ideas de Dios, pero no a algo que no estuviese presente en Dios desde la eternidad. En este sentido, los seres creados surgen de la esencia de Dios y no pueden surgir de ninguna otra cosa ajena a la divinidad. Asimismo, es obvia la similitud que esta propuesta tiene con la de Newton. Véase, además, el comentario de Sorabji a uno de los pasajes de Gregorio de Nisa en supra, n. 16.

49 En [63], pp. 260-261, Scholem nos dice que Luria:

"comenzó por formular una pregunta que da la apariencia de ser naturalista y, si se quiere, algo burda. ¿Cómo puede haber un mundo si Dios está en todas partes? Si Dios es 'todo en todo'+ , ¿cómo puede haber cosas que no sean Dios? ¿Cómo puede Dios crear el mundo a partir de [la] nada si no hay ninguna nada? Ésta es la pregunta. La solución, a pesar de la crudeza que él le dio, tuvo la mayor importancia en la historia del pensamiento cabalístico posterior. Conforme a Luria, Dios se vio llevado a hacer un espacio para el mundo abandonando, por así decir, una región dentro de sí mismo, una especie de espacio místico primordial del cual Él se retiró a fin de volver a él en el acto de la creación y de la revelación. El primer acto del En-Sof, del Ser Infinito es, por tanto, no un paso fuera, sino un paso dentro, un movimiento de retroceso, de caer sobre sí mismo, de retirarse dentro de sí mismo. En lugar de emanación, tenemos lo opuesto, contracción. El Dios que se revela a sí mismo en contornos firmes, fue superado por uno que descendió cada vez más a fondo en las profundidades de Su propio Ser, quien se concentró a Sí mismo en Sí mismo y esto lo había hecho desde el principio mismo de 
explicar la creación a partir de una contracción de Dios dentro de Sí mismo y, de esta contracción, Dios deja un hueco, un espacio vacío de todo, esto es, la nada, en la cual crear el mundo; pero, de lo anterior se puede decir que Dios crea el mundo en la nada, más bien que crearlo de la nada; lo que Dios use para llevar a cabo la Creación, será algo presente en Él desde toda la eternidad, lo que actualizará, para beneficio de los seres "creados". A pesar de todo, la importancia que esta propuesta tiene es que con ella se pretende dar un sentido literal a la formulación de Creación de la nada y se intenta mostrar cómo podría haberse realizado esto. Mi impresión más sincera es que las preguntas originales de Luria no admiten ninguna respuesta literal, sino sólo metafórica y, si no hay forma de explicar lo que sea crear el mundo de la nada, entonces parece que estamos obligados a aceptar que nuestro mundo y, obviamente, nosotros mismos, participamos de la sustancia de Dios y, por ello, el panteísmo es una conclusión que no puede evadirse o bien, si se puede, nosotros no tenemos la más remota idea de cómo hacerlo.

Veamos, ahora, lo que Newton nos dice acerca de su versión de la Creación:

Finalmente, la utilidad de la idea de cuerpo que he descrito, se hace patente por el hecho de que claramente comprende las verdades principales de la metafísica y a fondo las confirma y las explica, pues no podemos postular cuerpos de este tipo sin, al mismo tiempo, suponer que Dios existe y ha creado cuerpos, a partir de la nada, en el espacio vacío y que son seres distintos de las mentes creadas, pero capaces de combinarse con las mentes. ${ }^{50}$

Aquí me permito recordarles a mis lectores, la conclusión alcanzada en la sección en la que hablé de la noción newtoniana de espacio. Una de las cosas que espero haya quedado clara es que, conforme al planteamiento de Newton, el espacio no puede estar vacío, pues Dios lo llena plenamente o bien Dios contiene el espacio y no es el caso que el espacio lo contenga a Él. Ciertamente, en otra de las cosas que se leen en la cita, Newton no tiene razón, pues la Creación no puede ser de la nada, en sentido literal, ya que, conforme a una firme creencia newtoniana, el efecto debe estar contenido

la creación. Ciertamente, con frecuencia se tuvo la impresión, incluso por quienes le dieron una formulación teórica, que [la propuesta] rayaba en lo blasfemo; sin embargo, ésta resurgió una y otra vez, modificada, de manera ostensible, sólo por un 'esto es' o por un 'por así decir'".

+ La expresión figura en san Pablo, 1 Cor. 15, 28 y col. 3, 11 y, entre otros, la trae a colación Dionisio el seudo Areopagita; $c f r$. epígrafe a la sección III.

Véanse, en supra n. 46, un cuestionamiento similar al de Luria, con respecto a la posibilidad de una Creación de la nada, en la formulación de Escoto Erígena, 7 siglos anterior a Luria y, además, una propuesta, similar a la de Luria de que Dios formó una nada, previa a la Creación, en Gregorio de Nisa, según lo señala Sorabji, en supra, n. 16.

50 En [50], p. 142. 
plenamente en la causa y no hay más causa primera que Dios, por lo que la creación surge de las ideas de Dios, las que antes que los hombres existieran éstos no las conocían (ni podían hacerlo). En esta sección hemos leído algo acerca del heroico intento de Isaac Luria por dar una explicación de cómo podría ser una creatio ex nihilo en tanto que realizada por Dios, pero no es posible concebir algo así. Lo que, quizás, más se acerca a nuestra comprensión es la propuesta de Escoto Erígena quien finalmente fue acusado de panteísta.

En las otras cosas que leemos en la cita, Newton parece tener razón, pues ciertamente, la propuesta newtoniana de la Creación pone de manifiesto la presencia de Dios y la necesidad de ésta para la preservación del universo.

Finalmente, creo que Newton no se rehusaría a avalar (quizás en privado) una tesis panteísta pues, de esta manera, tendría a Dios cuidando plenamente el universo, que sería parte de su misma divina esencia. Recordemos el pasaje, en parte ya citado en supra, sección II:

Puesto que toda partícula de espacio, siempre y en todo momento indivisible de duración, está por doquier, ciertamente el Hacedor y el Señor de todas las cosas, no puede no estar nunca y en ningún lugar ${ }^{51}$ [...] Dios es el mismo Dios siempre y por doquier. Él es omnipresente, no sólo virtualmente, sino también sustancialmente; pues lo virtual no puede subsistir sin la sustancia. En él están contenidas todas las cosas y se mueven; empero, ninguna afecta a la otra; Dios nada sufre por el movimiento de las cosas; las cosas no encuentran ninguna resistencia por la omnipresencia de Dios. ${ }^{52}$

En este pasaje Newton mantiene que estamos contenidos en el seno de Dios; no hay ninguna distancia entre la divinidad y su Creación. ¿Podemos pensar que haya alguna diferencia sustancial entre Dios y su obra?

\section{A MANERA DE CONCLUSIÓN}

Con respecto a la forma que los artistas imponen desde fuera a las cosas materiales, hablamos de Rómulo como el fundador de Roma y, Alejandro, de Alejandría, adscribiendo la fundación de esas ciudades, no a los arquitectos y constructores, sino a los reyes por cuya voluntad, designio y mandato fueron construidas. Así, con mucha mayor razón, estamos obligados a llamar a Dios el fundador de las

51 En este pasaje leo a Newton diciendo, según se infiere de lo que sostiene en el texto citado: "[Dios] no puede no estar en algún tiempo y no puede no estar en algún lugar... ", lo cual, utilizando lógica modal se traduciría como: "Dios está necesariamente en todo tiempo y en todo lugar":

$\neg \exists x(t x \wedge \diamond \neg C(d, x)) \wedge \neg \exists x(1 x \wedge \diamond \neg F(d, x)) \equiv \forall x(t x \supset \square C(d, x)) \wedge \forall x(1 x \supset \square F(d, x))$

52 En [51], p. 545. 
naturalezas, pues él no las crea de material que él mismo no haya hecho, ni emplea trabajadores, excepto los de su propia creación. Y si él retirase, el que podemos denominar su "poder constructivo", de las cosas existentes, ellas dejarían de existir, así como no existían antes de que fuesen hechas. ${ }^{53}$

En las páginas anteriores he alegado que Newton, en su escrito "De gravitatione...", sostiene una posición panteísta, ya que los elementos de los que Dios se vale para llevar a cabo la Creación, conforme a la propuesta del escritor inglés, salen de Su misma esencia (pues de ninguna otra parte podrían salir).

Esta misma situación se presenta en la filosofía de Berkeley. En el caso de ambos pensadores, tenemos una propuesta creacionista en la que el material de la Creación son las ideas de Dios y la Creación misma es una teofanía: en ella se nos revela, de manera directa e inmediata, la obra de Dios; de forma más precisa, en ella vemos una estructuración de Sus ideas. En el caso de ambos pensadores, la ciencia nos daría cuenta de la relación entre tales ideas.

Sea por convicción o por razones menos aceptables, la propuesta newtoniana en filosofía natural está impregnada de una fuerte dosis de teología. Si volvemos a ver el "Escolio general", allí Newton señala que:

[De los cuerpos] [...] sus sustancias internas no las hemos de conocer ni por nuestros sentidos o por cualquier acto reflejo de nuestras mentes; mucho menos, entonces, tenemos alguna idea de la sustancia de Dios [...] pues todas nuestras nociones de Dios se toman de las formas de la humanidad por alguna semejanza la cual, aunque no es perfecta tiene, a pesar de todo, alguna similitud..$^{54} Y$ hasta

53 En [1] XII, 26 in fine [las cursivas son mías].

54 El seudo Dionisio Areopagita nos dice lo siguiente:

"Nos preguntamos ahora cómo nosotros podemos conocer a Dios, ya que Él no es percibido por los sentidos ni por la inteligencia ni es nada de las cosas que son. Con más propiedad diríamos que no conocemos a Dios por su naturaleza, puesto que ésta no es cognoscible y supera toda razón e inteligencia. Pero le conocemos por el orden de todas las cosas, en cuanto está dispuesto por Él mismo y que contiene en sí ciertas imágenes y semejanzas de sus ejemplares divinos, por el cual ascendemos al conocimiento de aquel Sumo Bien y fin de todos los bienes por camino [872A] acomodado a nuestras fuerzas. Pasamos por vía de negación y de trascendencia y por vía de la Causa de todas las cosas." [En [23], p. 339.]

En un sentido similar se expresa Escoto Erígena:

"pues como lo dice Dionisio el Areopagita, la Esencia de todas las cosas Él es, el único Quien es verdaderamente. 'Pues', nos dice 'el ser de todas las cosas es la Divinidad, Quien está por encima del Ser'. También Gregorio el Teólogo [Gregorio de Nisa] prueba, mediante muchos argumentos, que ninguna sustancia o esencia de criatura alguna, sea ésta visible o invisible, puede comprenderla el intelecto o la razón con respecto a lo que es; pues, así como Dios, tal como Él es en Sí Mismo, más allá de toda criatura, no lo comprende intelecto alguno, así Él 
aquí todo lo concerniente a Dios; discurrir de Él, a partir de las apariencias de las cosas, ciertamente pertenece a la Filosofía Natural. ${ }^{55}$

en donde Newton mantiene la necesidad de hablar de Dios en filosofía natural, para mostrar que no es un estudio separado del que nos da a conocer la estructura de nuestro universo y sus propiedades, aun cuando nunca llegaremos a conocer las reales propiedades intrínsecas, según el mismo autor lo señala.

En algún momento me pareció difícil comprender la necesidad de esta ceñida trama en la que la física (la filosofía natural) y la teología están trabadas; ahora me parece que Newton pudo señalar, de esta manera, que la nueva ciencia no tenía por qué embrollarse con problemas de la esencia y de las propiedades íntimas de las cosas, sino que podía llevar a cabo su tarea mediante la aplicación de las herramientas matemáticas y las adiciones alquímicas que él puso a funcionar en sus explicaciones de los fenómenos terrestres y celestes y sostener que, a pesar de que la nueva ciencia para nada tenía que (o ni siquiera podría) desentrañar los misterios teológicos, el mundo mismo tenía el pleno apoyo de la divinidad. Esto intentaré —en los últimos párrafos de este escrito- desmenuzarlo un poco más.

A Newton, en el texto del que aquí nos hemos ocupado, le preocupaban (al igual que a Berkeley, según lo he dicho) los problemas del escepticismo, la irreligión y el ateísmo que se seguiría de los dos anteriores, así como dar una buena explicación de los problemas de filosofía natural a los que Descartes se había enfrentado y los que, según Newton lo veía, no había resuelto satisfactoriamente. De acuerdo con su manera de ver las cosas, la versión del mundo que nos ofreció en "De gravitatione..." puede dar buena cuenta de los primeros problemas, pues el mundo que percibimos es Creación de Dios y, si mi lectura del texto es correcta, son las ideas mismas de Dios, bajo un ropaje sensible para que nosotros (y cualquier ser dotado de nuestros medios de conocimiento sensorial o de otros similares) podamos tener acceso a las mismas y, para conocer estas ideas, bastan nuestros sentidos. Así pues, no tenemos el problema del llamado "velo perceptual", lo que elimina la posibilidad, presente en la filosofía de Descartes, de ser escépticos con respecto a la realidad del "mundo exterior" y, junto con esto,

es igualmente incomprensible cuando se le considera en las profundidades más íntimas de la criatura que por Él fue hecha y que existe en Él; mientras que lo que sea que en cualquier criatura es percibido o bien por sentidos corpóreos o contemplado por el intelecto es tan sólo algún accidente de la esencia de cada criatura la que, como se ha dicho, es incomprensible por sí misma, pero que, sea por cualidad, cantidad, forma, materia, por alguna diferencia, por lugar o por tiempo se la conoce, no con respecto a qué es, sino con respecto a que es". [En [25] I, 3 [443A-443B]; p. 27.]

55 [51], p. 546 [las cursivas son mías]. 
desaparecen los peligros de la irreligión y del ateísmo pues, por lo anterior, tenemos una prueba palpable de la existencia de Dios a partir de la percepción de su obra y esto es una prueba, también, de la verdad de la religión, ya que ésta nos enseña que hay un Dios.

Una vez publicada su obra Philosophiæ naturalis principia mathematica (1687), Newton da una respuesta al otro problema señalado dos párrafos atrás, esto es, el de ofrecer una mejor explicación que la cartesiana de los problemas de filosofía natural y, para acallar críticas, tanto de Leibniz como de Berkeley, escribe, en la segunda edición de esta obra, el "Escolio general" y en él señala los límites de la investigación en filosofía natural (en ciencia), la que no nos va a aclarar los misterios de la esencia de Dios y, ni siquiera, la del más simple de los seres creados (creencia, ésta, que plenamente comparte con Descartes) ${ }^{56}$ Así, Newton hace una clara distinción entre los campos de investigación de ciencia, de ontología o metafísica y de teología, sin dejar de señalar, por otra parte, la relación ontológica central que él considera que se mantiene entre Dios y su Creación. ${ }^{57}$

Creo que la anterior es una forma adecuada de entender la profunda intromisión teológica en los escritos newtonianos de filosofía natural, pero

56 En las "Cuartas respuestas", a las objeciones de Arnauld — tras haber hecho, al respecto, algunas observaciones interesantes a su primer objetante, "un clérigo de los Países Bajos"Descartes señala, de manera categórica:

"Pues no estimo que aquí se requiera un conocimiento completo y perfecto de la cosa, como lo pretende el Señor Arnauld, sino que hay en esto la siguiente diferencia: que a fin de que un conocimiento sea completo y perfecto, el mismo debe contener todas y cada una de las propiedades que están en la cosa conocida y es por esto que no es sino Dios solo, quien sabe que hay conocimientos completos y perfectos de todas las cosas.

Pero, aun cuando hubiese un entendimiento creado que quizás tuviese, en efecto, los conocimientos completos y perfectos de múltiples cosas, sin embargo, jamás podría saber que los tiene, si Dios mismo no se lo revelase, en particular, pues para hacer que tenga un conocimiento pleno y completo de cualquier cosa, se requiere, tan sólo, que la potencia de conocer que está en él, iguale esta cosa, lo que se puede hacer fácilmente; pero, para hacer que él sepa que hay tal conocimiento o bien, que Dios nada ha puesto de más en esta cosa, que lo que él conoce de ella, es preciso que, por su poder de conocer, él iguale la potencia infinita de Dios, lo que es totalmente imposible." (En [22], VII, p. 220; IX-1, p. 171.)

57 Aquí me parece muy pertinente añadir lo que, a este respecto, Berkeley tiene que decir en su De motu:

“69. No negaré que la Mente que mueve y contiene esta masa corpórea universal y que es la verdadera causa eficiente del movimiento, hablando con propiedad y de manera estricta, es la misma causa de la comunicación del mismo. Sin embargo, en la filosofía física, debemos buscar las causas y las soluciones de los fenómenos entre los principios mecánicos. Por lo tanto, físicamente, una cosa no se explica al asignarle su verdadera causa activa e incorpórea, sino mostrando su conexión con los principios mecánicos, tales como la acción y la reacción son siempre opuestas e iguales. De tales leyes, como del principio primario y fuente, se extraen las reglas para la comunicación de los movimientos, las que, para el gran bien de las ciencias, ya han encontrado y demostrado los modernos." 
aún se podría apoyar más ésta, añadiendo que Dios no podría dejar de mantener en el ser este mundo, creación suya y dejar, según leemos en el epígrafe de san Agustín, que se perdiera en la nada, pues, además, no le es ajeno a Él, ya que está hecho plenamente de su íntima y más secreta esencia, por lo que, para Dios, "cuidar" el mundo es mantenerse a Sí mismo en el Ser.

Y más adelante, de manera precisa, Berkeley hace una importante distinción con respecto a los intereses y atribuciones de hombres de ciencia y metafísicos, al decir:

"71. En la física, los que ocupan el lugar central son el sentido y la experiencia, los que sólo se aplican a los efectos aparentes; en la mecánica se admiten las nociones abstractas de los matemáticos. En la filosofía primera o metafísica, nos ocupan las cosa incorpóreas, las causas, la verdad y la existencia de las cosas. El físico estudia la serie o la sucesión de las cosas sensibles, señalando las leyes que las conectan y en qué orden, qué es lo que precede como causa y qué es lo que se sigue como efecto. Y, conforme a este método, decimos que el cuerpo en movimiento es la causa del movimiento en el otro."

Y, finalmente, leemos:

"72. Sólo por la meditación y por el razonamiento pueden rescatarse las verdaderas causas activas de la oscuridad que las rodea y ser comprendidas en alguna medida; tratarlas es la tarea de la filosofía primera o metafísica: concederle a cada ciencia su propia provincia, asignarle sus límites, distinguir con precisión los principios y los objetos que a cada una pertenecen. De esta manera será posible tratarlas con mayor facilidad y claridad." En [12], $\S \S 69,71-72$; véanse, además, ibid., §§28-37. Aquí me parece pertinente citar, además de las anteriores, parte del $\S 34$ :

"34. Los pensadores modernos consideran el movimiento y el reposo en los cuerpos como dos estados de existencia, en cualquiera de los cuales cada cuerpo, sin presión de ninguna fuerza externa, permanecería naturalmente pasivo; de lo que se podría suponer que la causa de la existencia del cuerpo en diferentes partes del espacio es también la causa de su movimiento y reposo; pues parecería que no habría que buscar ninguna otra causa para la existencia sucesiva del cuerpo en diferentes partes del espacio que aquella causa de la que se deriva la sucesiva existencia del mismo cuerpo en diferentes partes del tiempo. Pero, tratar del bueno y gran Dios, creador y preservador de todas las cosas y mostrar cómo todas las cosas dependen del ser supremo y verdadero, aun cuando es la parte más excelente del conocimiento humano, sin embargo pertenece, más bien, a la provincia de la filosofía primera o metafísica y a la teología, más que a la filosofía natural la que, hoy en día, está confinada, casi totalmente, a experimentos y mecánica y, así, la filosofía natural o bien presupone el conocimiento de Dios o lo toma de alguna ciencia superior. .." 
BIBLIOGRAFÍA

ANTOLOGÍAS, ENCICLOPEDIAS, DICCIONARIOS, ETC.

〈1〉 Abbagnano, Nicola, Diccionario de filosofía [traducción del italiano, de Dizionario de filosofía (1961), por Alfredo N. Galletti], Fondo de Cultura Económica, México, 1963.

$\langle 2\rangle$ Aristotle, The Works of Aristotle [translated into English under the editorship of W.D. Ross, M.A., Hon. LL.D. (Edim.)], vols. I-X, Oxford at the Clarendon Press 1908-1931.

33〉 Barrow, Isaac (1630-1677), The Mathematical Works of Isaac Barrow, D.D. (Master of Trinity College, Cambridge). Edited for Trinity College by W. Whewell, D.D. (Master of the College). Cambridge: Printed at the University Press, 1860.

44) Bechler, Zev, Contemporary Newtonian Research, D. Reidel Publishing Company; Dordrecht/Boston, 1982.

〈5〉 Benítez, Laura y José A. Robles (comps.), El problema de la relación mente-cuerpo, Instituto de Investigaciones Filosóficas-unam, México, 1993.

$\langle 6\rangle$ — Materia, espacio y tiempo: de la filosofía natural a la física, Facultad de Filosofía y Letras (DEP)-unAm, México, 1999.

〈7〉 Berkeley, G., The Works of George Berkeley Bishop of Cloyne (1948-1957) A.A. Luce, T.E. Jessop (eds.), Thomas Nelson and Sons Ltd., Londres, 1964 (1a. reimpresión), vols. I-IX.

$\langle 8\rangle$ - Comentarios filosóficos, Introducción manuscrita a Los principios del conocimiento humano, Correspondencia con Johnson, introducción, traducción y notas de José Antonio Robles, Instituto de Investigaciones Filosóficas-unam, México, 1989.

〈9〉 Descartes, R., OEuvres de Descartes, Publiées par Charles Adam et Paul Tannery (1896-1913). Ouvrage publié avec le concours du Centre National du Livre. Librairie Philosophique J. Vrin, 1996, vols. I-XI.

$\langle 10\rangle$ Diógenes Laercio, Lives of Eminent Philosophers, traducción al inglés del texto griego, por R.D. Hicks, Loeb Classical Library/Harvard University Press, Cambridge, 1970, 2 vols.

〈11〉 Dionisio, el seudo Areopagita, Obras completas del Pseudo Dionisio Areopagita, edición preparada por Teodoro H, Martín-Lunas, presentación por Olegario González de Cardenal, Biblioteca de Autores Cristianos, Madrid, MCMXCV (segunda edición).

$\langle 12\rangle$ Epicuro, The Extant Remains (1926, Oxford, at the Clarendon Press). Con breve aparato crítico, traducción y notas de Cyril Bailey, Georg Olms VerlagHildesheim, Nueva York, 1975.

〈13〉 Gillispie, Ch. C., Dictionary of Scientific Biography (1970), Charles Scribner's Sons, New York, 1980, vols. 1-16.

〈14〉 Hume, David, Enquiries Concerning Human Understanding and Concerning the Principles of Morals, reimpresas de la edición póstuma de 1777 y editadas 
con Introducción, Tabla comparativa de contenidos e Índice analítico por L.A. Selby-Bigge, Oxford at the Clarendon Press; segunda edición, 1902.

$\langle 15\rangle$ Locke, John, La conducta (sic) del entendimiento y otros ensayos póstumos, edición bilingüe, introducción, traducción y notas de Ángel M. Lorenzo Rodríguez. Ánthropos, Editorial del Hombre, Barcelona, 1992.

$\langle 16\rangle-$, et al., Obras varias y correspondencia de (y sobre) John Locke, selección, traducción, introducción y notas de José Antonio Robles y Carmen Silva. Colección $\sum$, Universidad Autónoma Metropolitana-Unidad Iztapalapa, México, 1991.

$\langle 17\rangle$ Malebranche, N., OEuvres complètes, 2a. ed., Ouvrage publié en coédition avec le Centre National de la Recherche Scientifique, Librairie Philosophique J. Vrin, París, 1972-1978, tt. I-XX.

$\langle 18\rangle$ Newton, Isaac, Unpublished Scientific Papers, a selection from the Portsmouth Collection in the University Library, Cambridge (1962), selección, edición y traducción de A. Rupert Hall y Marie Boas Hall, Cambridge University Press, Cambridge/Londres/Nueva York/Melbourne, 1978 (primera edición a la rústica).

〈19〉 O’Meara, John J. y Bieler, Ludwig (eds.), The Mind of Eriugena, Papers of a Colloquium, Dublin 14-18, julio 1970, Irish University Press, for the Royal Irish Academy, Dublín, 1973.

$\langle 20\rangle$ Platón, The Dialogues of Plato, traducidos al inglés por B. Jowett, M.A., con una introducción del profesor Raphael Demos, en dos volúmenes, Random House, Nueva York, 1937, 15a. impresión de la 3a. y última edición de la traducción de Jowett. Consulté, asimismo, Platon: OEuvres complètes, texto establecido y traducido por Albert Rivaud, Société d'édition "Les belles lettres”, París, 1956 3a. ed., corregida y aumentada, t. X, Timée y Critias.

〈21〉 Popkin, Richard H. (ed.), Millenarianism and Messianism in English Literature and Thought 1650-1800, Clark Library Lectures: 1981-1982, E.J. Brill, Leiden/New York/Kobenhavn/Köln, 1988. Robles, José Antonio y Silva, Carmen (comps.), cfr. supra, $\langle 12\rangle$.

$\langle 22\rangle$ Sorabji, Richard (ed.), Philoponous, and the Rejection of Aristotelian Science, Cornell University Press, Ithaca, Nueva York, 1987.

$\langle 23\rangle-$, Aristotle Transformed, the Ancient Commentators and Their Influence, Cornell University Press, Ithaca, New York, 1990.

OBRAS INDIVIDUALES:

[1] Agustín de Hipona, San, De Civitate Dei (1467), traducción de Henry Bettenson, Concerning The City of God against the Pagans (1972), 3a. reimpresión, con una introducción de David Knowles, Penguin Books Ltd., Harmondsworth, 1980.

[2] Algra, Keimpe A., Concepts of Space in Greek Thought, E.J. Brill/Leiden, Nueva York/Köln, 1995.

[3] Aristotle, Aristotle's Metaphysics (1924), A revised text with introduction and commentary by W.D. Ross, vol. I: Books A-E; vol. II: Books Z-N, Clarendon Press, Oxford, 1958. 
[4] — Physique, t. I (Libros I-IV) 1952, 2a. ed. (1952); t. II (Libros V-VIII) 1961, 3a. edición, revisada y corregida. Texto establecido y traducido al francés por Henri Carteron. Societé d'édition "Les belles lettres", París.

[4'] — , Physica, trad. de R.P. Hardie y R.K. Gaye (1930), en $\langle 2\rangle$, vol. II: Physica, De cælo, De generatione et corruptione.

[5] — De cælo, trad. de J.L. Stocks, M.A., D.S.O. (1922), en $\langle 2\rangle$, vol. II.

[6] Arnauld, A., Des Vrayes et des Fausses Idées contre ce qu'enseigne l'auteur de la Recherche de la verité (1683), publicado por Nicolas Schooten en Colonia. Hay una reimpresión por Librairie Arthème Fayard, 1986 (Corpus des OEuvres de Philosophie en Langue Française), revisada por Christiane Frémont, en la que se ha modernizado la tipografía, pero se mantuvieron la ortografía y la puntuación originales.

[7] Barrow, Isaac, Lectiones geometricæ, (1669), recogidas en $\langle 3\rangle$.

[8] Benítez, Laura y J.A. Robles, El espacio y el infinito en la modernidad, con una presentación de Alberto Cordero Lecca. Publicaciones Cruz O., S.A., México, 2000.

[9] Berkeley, G, Philosophical Commentaries Generally Called the Commonplace Book, An editio diplomatica transcribed and edited with introduction and notes by A.A. Luce MC DD Litt D Thomas Nelson and Sons Limited, Londres, 1944. En 〈7〉 I, pp. 9-104 figuran los Comentarios y pp. 107-139 figuran las notas (breves, en comparación con la edición independiente) de Luce a las entradas de Berkeley. En $\langle 8\rangle$ pp. 17-128 figura una traducción al castellano de los Comentarios, sin las notas de Luce.

[10] — - A Treatise Concerning the Principles of Human Knowledge (1710). En 〈7〉 II, pp. 1-17 (introducción de TE. Jessop), 19-113 (el texto).

[11] — - Three Dialogues between Hylas and Philonous (1713). En 〈7〉 II, pp, 14761 (introducción de T.E. Jessop), pp. 163-263 (el texto).

[12] — - "De Motu sive de motus principio \& natura, et de causa communicationis motuum" (1721); trad. al inglés de A. A. Luce: "Of Motion or the Principle and the Nature of Motion and the Cause of the Communication of Motions". En $\langle 7\rangle$ IV, pp. 3-7 (introducción de Luce), 11-30 (texto en latín); 31-52 (traducción de Luce).

[13] — - "Philosophical Correspondence between Berkeley and Samuel Johnson. 1729-1730". En $\langle 7\rangle$ II, pp. 267-270 (introducción de T.E. Jessop), 271294. Una traducción al castellano se encuentra en $\langle 8\rangle$ ("Correspondencia con Johnson"), pp. 223-50. En este escrito usamos esta traducción; en nuestras citas, ponemos la paginación de la siguiente manera: $f / c$, en donde "f" es la(s) pág(s). del texto en inglés y "c" remite a la(s) pág(s). de la traducción de Robles.

[14] — - Alciphron or the Minute Philosopher (1732). En $\langle 7\rangle$ III, pp. 1-20 (introducción de T.E. Jessop), pp. 21-29 (portada facsimilar, advertencia e índice de diálogos y secciones), pp. 31-329 (texto), pp. 331-335 (apéndice I) y pp. 336-337 (apéndice II). Hay traducción al castellano, Alcifrón o el filósofo minucioso, de Pablo García Castillo, con introducción y notas de Cirilo Flórez Miguel, Ediciones Paulinas, Madrid, 1978. 
[15] Bolton, Martha B., "El mecanicismo del siglo xvi y las potencias causales: ¿qué es lo incorrecto en el caso de la virtus dormativa?" En $\langle 6\rangle$, pp. 55-71.

[16] Charleton, Walter, Physiologia Epicuro-Gassendo-Charletoniana, or a Fabrick of Science Natural, upon the Hypothesis of Atoms, Founded Epicurus Repaired by Petrus Gassendus Augmented Walter Charleton Dr. in Medicine, and Physician to the late Charles, Monarch of Great Britain. Reimpreso de la edición de Londres de 1654, con índices y una nueva introducción de Robert Hugh Kargon, Department of The History Science, The Johns Hopkins University, The Sources of Science, no. 31, Johnson Reprint Corporation, Nueva York/Londres, 1966.

Clarke, S., véase [16] Leibniz, G.W., Clarke, S.

[17] Cudworth, Ralph, The True Intellectual System of the Universe: the First Part; wherein, All the Reason and Philosohy of Atheism is Confuted; and Its Impossibility Demonstrated, Londres, printed for Richard Royston, Bookseller to His most Sacred MAJESTY, MDCLXXVIII.

[18] Descartes, René, Le monde ou traité de la lumière. En $\langle 9\rangle$ XI, pp. 1-118. Existe una traducción al castellano: René Descartes, El mundo o tratado de la luz, estudio introductorio, traducción y notas de Laura Benítez, Instituto de Investigaciones Filosóficas-unAm, México, 1986. En este escrito usamos esta traducción; en nuestras citas, ponemos la paginación de la siguiente manera: f/c, en donde "f" es la(s) pág(s). del texto en francés y "c" remite a la(s) pág(s). de la traducción de Benítez.

[19] Descartes, R., "Correspondance (Mai 1647-Février 1650)". En $\langle 9\rangle$ V.

[20] — Les meditations metaphysiques. En $\langle 9\rangle$ (latín: VII, pp. 1-90) IX-1, pp. 172.

[21] — Les principes de la philosophie (1647). En $\langle 9\rangle$ IX-2.

[22] —_ Objections faites par des personnes tres doctes contre les precedents Meditations, avec les réponses de l'auteur. En $\langle 9\rangle$ (latín: VII, pp. 91-561) IX-1, pp. 73-248.

[23] Dionisio, el seudo Areopagita, "Los nombres de Dios". En 〈1〉, pp. 269-368.

[24] Epicuro, "Carta a Heródoto". En $\langle 10\rangle$, pp. v-nn.

$\left[24^{\prime}\right]$ — - "Epistula ad Herodotum". En $\langle 12\rangle$, pp. 18-55, carta y pp. 173-258 el comentario.

[25] Eriugena, Johannes Scotus, Periphyseon (Division of Nature), traducido de John O’Meara, Cahiers d'études médievales, Cahier spécial 3; Éditions Bellarmin, Montréal, Qc., 1987.

[26] Funkenstein, Amos, "The Body of God in the 17th Century Theology and Science". En $\langle 21\rangle$, pp. 149-175.

[27] Furley, David, "Summary of Philoponus' Corollaries on Place and Void". En $\langle 22\rangle$, pp. 130-139.

[28] Gilbert, Neil B., “Telesio, Bernardino”. En $\langle 13\rangle$ 13, pp. 277-280.

[29] Grant, E., Much Ado About Nothing. Theories of space and vacuum from the Middle Ages to the Scientific Revolution. Cambridge University Press, Cambridge, 1981. 
[30] Hume, David, Enquiry concerning Human Understanding (1748). En $\langle 14\rangle$, pp. 1165.

[31] Jammer, Max, Concepts of Space: The History of Theories of Space in Physics (1954/1969). 1st. Dover ed. Nueva York, 1993. En esta edición Jammer añadió un capítulo a su obra. Hay traducción al castellano, Conceptos del espacio, de la 1a. ed. de la publicación original de Harvard University Press, Cambridge, Mass., 1957 (1954, según se indica en la pág. legal de la traducción, hubo una segunda edición de Harvard en 1969), traducción realizada por Daniel Cazés, Editorial Grijalbo, S.A., México, D.F., 1970.

[32] Koyré, Alexandre, Newtonian Studies (1965), Phoenix Books/The University of Chicago Press, Chicago, 1968.

[33] Leibniz, G.W., S. Clarke, The Leibniz-Clarke Correspondence, together with extracts from Newton's Principia and Opticks, edited with introduction and notes by H.G. Alexander, Manchester University Press. Barnes \& Noble, Nueva York, 1956. Existe, también, una versión francesa, que es: Correspondance Leibniz-Clarke (1715-1716). Presentée d'après les manuscrits originaux des bibliotheques de Hanovre et de Londres, par André Robinet, Presses Universitaires de France, París, 1957.

[34] Locke, J., An Essay Concerning Human Understanding, Collated and annotated, with prolegomena, biographical, critical, and historical by Alexander Campbell Fraser. Dover Publications, Inc., Nueva York, 1959.

[34'] — - An Essay Concerning Human Understanding, Edited with an introduction, critical apparatus and glossary by Peter H. Nidditch (1975), Oxford at the Clarendon Press, Oxford, 1979.

[35] — - Of the Conduct of the Understanding [La conducta (sic) del entendimiento]. En $\langle 15\rangle$, pp. 2-203 (páginas pares inglés, páginas impares castellano).

[36] — Elements of Natural Philosophy [Nociones de filosofía natural]. En $\langle 15\rangle$, pp. 204-271 (páginas pares inglés, páginas impares castellano).

[37] —_ "Examen de la opinión del P. Malebranche de ver todas las cosas en Dios". En $\langle 16\rangle$, pp. 35-81.

[38] [Tito] Lucrecio Caro, De la naturaleza de las cosas, traducción e introducción de René Acuña, Coordinación de Humanidades/Dirección general de Publicaciones-unam, México, 1981. Esta traducción carece de la enumeración de las líneas del poema.

$\left[38^{\prime}\right]$ — De la natura de las cosas, traducción, introducción, versión rítmica y notas de Rubén Bonifaz Nuño, Instituto de Investigaciones Filológicas/Centro de Estudios Clásicos-unam, México, 1984.

$\left[38^{\prime \prime}\right]$ — - De la nature, traduction nouvelle, couronée par l'Académie Française, introduction et notes de Henri Clouard, Édition revue et corrigée, Éditions Garnier Frères, París, 1954.

[39] Malebranche, N., De la recherche de la verité, où l'on traite de la nature de l'esprit de l'homme, et de l'usage qu'il en doit faire pour éviter l'erreur des Sciences (1674; 6ème. édition, 1712), Édité par Geneviève Rodis Lewis; avant propos de Henri Gouhier, tt. I-III de $\langle 17\rangle$. 
[40] — Conversations chrétiennes, dans lesquelles on justifie la vérité de la religion et de la morale de Jésus-Christ. Publié par André Robinet (seconde édition, 1972), t. IV de $\langle 17\rangle$.

[41] — - Recueil de toutes les réponses a Monsieur Arnauld, Édité par André Robinet, t. VI: Réponse au livre Des vraies et des fausses idées trois lettres touchanit la défense de M. Arnauld, t. VII: Lettres touchant celles de M Arnauld dissertation sur les miracles, t. VIII: Réponse au Livre I des réflexions philosophiques, t. IX: Réponse a la troisième lettre de M. Arnauld Réponse aux lettres I et II de M. Arnauld Lettres I, II et III d'Arnauld Écrit contre la prévention et abrégé du $T N G$, tt. VI-IX de $\langle 17\rangle$.

[42] McGuire, J.E., "Body and Void and Newton's De Mundi Systemate: Some New Sources", Archive for the History of Exact Sciences, 3, 1966, pp. 206-48.

[43] —_ "Force, Active Principles and Newton's Invisible Realm", Ambix, 15, 1968, pp. 154-208.

[44] _ _ "Existence, Actuality and Necessity: Newton on Space and Time", Annals of Science, 35, 1978, pp. 463-508.

[45] — - "Newton on Place, Time and God: an Unpublished Source", The British Journal for the History of Science, vol. 11, no. 38, 1978.

[46] _ - "Space, Infinity and Indivisibility: Newton on the Creation of Matter". En 〈4〉, pp. 145-190.

[47] —y P.M. Rattansi, "Newton and the 'Pipes of Pan'", Notes and Records of the Royal Society, 21, 1966, pp. 108-1043.

[48] Mopsick, Charles, Les grands textes de la cabale, les rites qui font Dieu. (Les dix paroles) Éditions Verdier, 1120 Lagrasse, 1993.

[49] Nadler, Steven: "Knowledge, Volitional Agency and Causation in Malebranche and Geulincx", British Journal for the History of Philosophy, vol. 7, nbr. 2, junio 1999, pp. 263-274.

[50] Newton, Sir Isaac: “De gravitatione et æquipondio fluidorum”. En $\langle 18\rangle$, pp. 89156. En 75-88, introducción a los escritos de mecánica; de 89-90, breve presentación del MS. Add. 4003; de 90-121 texto latino; de 121-56, traducción al inglés.

[51] — - Philosophiæ naturalis principia mathematica, 3a. ed. (1726) with variant readings. Assembled and edited by Alexandre Koyré and I. Bernard Cohen, with the assistance of Anne Whitman, vol. I. Harvard University Press, Cambridge, Mass., 1972.

[51'] — Mathematical Principles of Natural Philosophy and His System of the World, traducción al inglés de Philosophiæ naturalis principia mathematica (1687), por Andrew Motte (1729), revisada y ampliada con un apéndice histórico y explicativo por Florián Cajori (1934), University of California Press, Berkeley/Los Ángeles/Londres, 1962. Vol. I: El movimiento de los cuerpos, vol. II: El sistema del mundo

[52] — Opticks or a Treatise of the Reflections, Refractions, Inflections \& Colours of Light (1704), based on the 4a. ed., Londres, 1730. With a Fore-word by Albert Einstein; an Introduction by Sir Edmund Whittaker, a Preface by I. 
Bernard Cohen, and an Analytical Table of Contents prepared by Duane H.D. Roller. Dover Publications, Inc., Nueva York, 1979.

[53] Pascal, B., Pensées, prefacio e introducción de Léon Brunschvicg, Librairie Générale Française, París, 1972.

[54] Patrizi, Francesco, De spacio physico et mathematico, présentation, traduction et notes par Héléne Védrine, Librairie Philosophique J. Vrin. París, 1996. Véase, también, de Spacio Physico, traducido al inglés por Benjamin Brickman, Journal of the History of Ideas, 4, 1943, pp. 224-245. Las remisiones a estos textos, las haré de la siguiente manera: "[39] p/q", remite a este escrito, donde "p" es la pág. de Védrine y "q" la pág. de Brickman; cuando sea el caso, usaré “[39] (p/q)/r", en donde "(p/q)" se refiere a Védrine, "p" a la pág. donde figura el texto en latín y "q" a la pág. donde figura el texto en francés; " $r$ " remite a la pág. en Brickman.

[55] Platón, Timæus (Timeo). En $\langle 20\rangle$ II, pp. 3-68. En la edición francesa, "Notice", pp. 3-123; Timée, 125-228.

[56] Robles, José A., "Berkeley: mente e ideas". En $\langle 5\rangle$, pp. 73-100.

[57] —- "Espacio, materia y tiempo en cuatro filósofos atomistas: Epicuro (341-270), Lucrecio ((98-55), Francesco Patrizi (1529-1597) y Walter Charleton (1620-1707)". En $\langle 6\rangle$, pp. 146-82.

[58] — - "Inteligibilidad y cualidades sensibles: de Descartes a Berkeley o de la resurrección de las cualidades secundarias". En Diánoia. Anuario de Filosofía, XLIV, 1998, Instituto de Investigaciones Filosóficas-unAm/Fondo de Cultura Económica, México, 1999, pp. 33-61.

[59] __ "Isaac Newton: ¿berkeleyano avant la lettre?, Revista Latinoamericana de Filosofía, vol. XXVI, no. 2 (primavera 2000), pp. 199-224.

—- Véase, en supra, Benítez, Laura y Robles, José A.

[60] Rohault, Jacques, Rohault's System of Natural Philosophy, illustrated with Dr. Samuel Clarke's Notes, taken mostly of Sir, Isaac Newton's Philosophy, with Additions. Done into English by John Clarke, D.D. Dean of Sarum. Printed for James y John Knapt; Londres, MDCCXXIX; 2a. ed., 2 vols, Garland Publishing, Inc., Nueva York/Londres, 1987.

[61] Ross, W.D., Aristóteles, traducción al castellano de Aristotle (1923), por Diego F. Pró, Editorial Sudamericana, Buenos Aires, 1957.

[62] Scholem, Gershom G., Major Trends in Jewish Mysticism, Schocken Books, Nueva York, 1974.

[63] —- Conceptos básicos del judaísmo: Dios, Creación, Revelación, Salvación, traducción del alemán, de Über einige Grundbegriffe des Judentums (1970), por José Luis Barbero. Editorial Trotta, Colección Paradigmas, Madrid, 1998.

[64] Sorabji, Richard, Time, Creation, and the Continuum, Cornell University Press, Ithaca/Nueva York, 1983.

[65] — Matter, Space, \& Motion, Theories in Antiquity and Their Sequel, Cornell University Press, Ithaca/Nueva York, 1988.

[66] — _ "John Philoponus". En $\langle 22\rangle$, pp. 1-40.

[67] — - "Infinity and the Creation". En $\langle 22\rangle$, pp. 164-178. 
[68] — - "Infinite Power Impressed: the Transformation of Aristotle's Physics and Theology". En $\langle 23\rangle$, pp. 181-198.

[69] Struik, Dirk J. (ed.), A Source Book in Mathematics, 1200-1800, Harvard University Press, Cambridge, Mass., 1969.

[70] Trouillard, Jean, "Érigène et la théophanie créatrice". En $\langle 19\rangle$, pp. 98-113.

[71] Wéber, E.H., La personne humaine au XIIIe siécle, Librairie Philosophique J. Vrin, París, 1991.

[72] Westfall, Richard S., Never at Rest. A Biography of Isaac Newton (1980), Cambridge University Press, Cambridge, 1982, 2a. reimpresión.

Recibido: 13 de diciembre de 2000. 